\title{
Managerial Talent, Motivation, and Self-Selection into Public Management
}

\author{
Josse Delfgaauw \\ Robert Dur
}

Department of General Economics, Erasmus School of Economics, Erasmus University Rotterdam, and Tinbergen Institute. 


\section{Tinbergen Institute}

The Tinbergen Institute is the institute for economic research of the Erasmus Universiteit Rotterdam, Universiteit van Amsterdam, and Vrije Universiteit Amsterdam.

Tinbergen Institute Amsterdam

Roetersstraat 31

1018 WB Amsterdam

The Netherlands

Tel.: +31(0)205513500

Fax: $+31(0) 205513555$

Tinbergen Institute Rotterdam

Burg. Oudlaan 50

3062 PA Rotterdam

The Netherlands

Tel.: + $31(0) 104088900$

Fax: $+31(0) 104089031$

Most TI discussion papers can be downloaded at http://www.tinbergen.nl. 


\title{
Managerial Talent, Motivation, and Self-Selection into Public Management*
}

\author{
Josse Delfgaauw $^{\dagger}$ and Robert Dur ${ }^{\ddagger}$
}

October 14, 2008

\begin{abstract}
The quality of public management is a recurrent concern in many countries. Calls to attract the economy's best and brightest managers to the public sector abound. This paper studies self-selection into managerial and non-managerial positions in the public and private sector, using a model of a perfectly competitive economy where people differ in managerial ability and in public service motivation. We find that, if demand for public sector output is not too high, the equilibrium return to managerial ability is always highest in the private sector. As a result, relatively many of the more able managers self-select into the private sector. Since this outcome is efficient, our analysis implies that attracting a more able managerial workforce to the public sector by increasing remuneration to private-sector levels is not cost-efficient.
\end{abstract}

Keywords: Public Management; Public Service Motivation; Managerial Ability; Self-Selection.

JEL-codes: H83, J24, J3, J45

\footnotetext{
${ }^{*}$ We are grateful to Margaretha Buurman, Maitreesh Ghatak, Otto Swank, seminar participants in Rotterdam, and conference audiences at the CESifo Area Conference on Public Economics 2008 in Munich, the 2008 PEUK Public Economics Conference at Warwick University, the 4th SFB/TR15 Workshop at Humboldt University Berlin, and the 2008 Annual Congress of the European Economic Association in Milan for useful discussions and comments.

${ }^{\dagger}$ Department of Economics, Erasmus University Rotterdam, and Tinbergen Institute. Address: Erasmus University, FEW/H 8-24, P.O. Box 1738, 3000 DR Rotterdam, The Netherlands. E-mail: delfgaauw@few.eur.nl

${ }^{\ddagger}$ Department of Economics, Erasmus University Rotterdam, Tinbergen Institute, CESifo, and IZA. Address: Erasmus University, FEW/H 8-15, P.O. Box 1738, 3000 DR Rotterdam, The Netherlands. E-mail: dur@few.eur.nl
} 


\section{Introduction}

The quality of management in the public sector is a recurrent concern in many countries. Part of this concern is based on the perception that the public sector is an unattractive employer for high-quality managers. Inferior remuneration and weak financial incentives attract less talented managers to the public sector and lead them to put little effort in their job. For the US, this is nicely illustrated by the report of the National Commission on the Public Service (2003), which concludes that "recognition that there is much wrong with the current organization and management of the public service is widespread today." (p.2) and that "too few of our most talented citizens are seeking careers in government" (p.iv). Moreover, "too many of the best recruits are rethinking their commitment, either because they are fed up with the constraints of outmoded personnel systems and unmet expectations for advancement or simply lured away by the substantial difference between public and private sector salaries in many areas" (p.8).

Not only policy makers are concerned about the quality of management in the public sector. Employees in the public sector have similar concerns and 'vote with their feet', as is illustrated by Table 1. This table reports data from a survey conducted by the Dutch Ministry of the Interior and Kingdom Relations among workers who have quit a public sector job to take a private sector job or vice versa in 2002 in the Netherlands. The second and third column of Table 1 list the percentage of workers who claim that management aspects had been one of the three most important reasons to quit their former job, for various parts of the public sector. ${ }^{1}$ Clearly, workers who moved from the public sector to the private sector mention management aspects substantially more often than workers who moved in the opposite direction.

Several policy makers have called for a change: The public sector should attempt to attract the economy's best and brightest managers. In the words of the National Commission on the Public Service (2003): "Salaries for

\footnotetext{
${ }^{1}$ Respondents could choose from a list of 19 potential reasons for leaving one's job, including items like salary, promotion prospects, atmosphere, and responsibilities. Table 1 gives the percentages of people who among the three most important reasons list either personnel policies, general management of their unit, or supervision. Similar results arise if we single out each of these categories. Also, restricting attention to the single most important reason for leaving or to people who do not supervise anyone themselves do not alter the general picture.
} 
Table 1: Percentage of workers moving from the private sector to the public sector and vice versa who mention management aspects as one of the three most important reasons to leave their former job

\begin{tabular}{|c|c|c|c|c|}
\hline \multirow[b]{2}{*}{ Sector } & \multicolumn{2}{|c|}{$\%$ of people moving } & \multicolumn{2}{|c|}{$\begin{array}{l}\text { Number of } \\
\text { respondents }\end{array}$} \\
\hline & Inflow & Outflow & Inflow & Outflow \\
\hline Central & 33.9 & 61.3 & 329 & 134 \\
\hline Local & 40.4 & 65.9 & 681 & 267 \\
\hline Police & 31.3 & 71.5 & 444 & 95 \\
\hline Research $^{1}$ & 30.7 & 66.3 & 128 & 31 \\
\hline Hospitals $^{2}$ & 41.3 & 53.4 & 40 & 46 \\
\hline Defence & 25.6 & 63.5 & 159 & 107 \\
\hline Education & 35.5 & 47.5 & 432 & 145 \\
\hline
\end{tabular}

Data source: BZK, Mobiliteitsonderzoek 2002.

All differences between inflow and outflow are significant at the $1 \%$ level except for the sector Hospitals.

${ }^{1}$ Research consists of universities and research institutes.

2 Only university hospitals were surveyed.

[executives in government] should be based on the compelling need to recruit and retain the best people possible." ${ }^{2}$ This paper questions this view. In a nutshell, we show that, if demand for public sector goods is not too high, perfect competition on all markets results in an equilibrium where relatively few of the more able managers seek employment in the public sector. The equilibrium is efficient, both from the point of view of a social planner as well as of a policy maker aiming to deliver a certain amount of publicly provided goods at lowest cost. Hence, attempts to attract a more able managerial workforce to the public sector by increasing remuneration to private-sector levels are not efficient.

We develop a model of a perfectly competitive economy with two job types, worker and manager, and two sectors, the public and the private sector. The sectors differ only in the kind of good that is produced; pro-

\footnotetext{
${ }^{2}$ Similar recommendations can be found in a report from the OECD (2001) that studies countries' experiences with recruiting and retaining public sector personnel. The report concludes that "The public sector is not usually able to compete with the salaries offered by private employers, especially those of highly-educated personnel and managers. However, pay increases may be necessary to prevent an outflow of highly-qualified personnel." (p. 29)
} 
duction technology and the institutional environment are assumed identical. Production takes place in units consisting of one manager and one or more workers, where the number of workers is chosen by the manager. Output is homogeneous within a sector, and is sold at the market-clearing price. Further, workers receive a market-clearing wage and managers are residual claimants of their unit. ${ }^{3}$ Within a unit, two types of tasks complement each other in production: managerial tasks and non-managerial tasks. Workers only exert effort on non-managerial tasks, while managers may exert effort on both tasks. ${ }^{4}$

Crucially, people in our economy differ in two characteristics. First, people differ in managerial talent. Talent increases the effectiveness of one's effort spent on managerial tasks. As we shall see, in equilibrium better managers focus on managing and spend less effort on non-managerial tasks; instead, they hire additional workers. As a result, better managers lead larger organisations, earn more income, and attain higher utility. For people with low managerial ability, taking a job is more attractive than managing a unit, as the residual return of their unit would be too small. These results are close in spirit to Rosen (1982).

Second, people in our economy differ in public service motivation (PSM), which we define as a relative preference for working in the public sector. Public service motivation can arise from a preference for tasks specific to the public sector, for contributing to goals specific to public organisations, or for helping the specific set of clients that is served by public organisations in sectors like health care and education. ${ }^{5}$ For convenience, we assume that a person's PSM is independent of job type or effort. More importantly, we

\footnotetext{
${ }^{3}$ This may seem to be a far cry from real-world production and wage determination in the public sector. However, this setup allows us to analyse self-selection of people into jobs when no restrictions are being imposed, which gives the efficient allocation. This serves as a benchmark for evaluating attempts to improve upon the pool of people opting for public management.

${ }^{4}$ Examples of managers who also perform non-managerial tasks abound. For instance, senior surgeons in hospitals both perform surgery and supervise assistants; deans in academia tend to spend time on managing as well as on teaching and research; and managers in consultancy firms usually engage in supervision of (junior) staff as well as in provision of advice to (the more important) clients.

${ }^{5}$ Recent studies on the motivation of workers in the public sector include Antonazzo et al. (2003) on nursing workers, Edmonds et al. (2002) on teachers, and Frank and Lewis (2004) on employees in these and several other areas of the public sector. Le Grand (2003, ch.2) and Perry and Hondeghem (2008) provide overviews of the empirical literature on PSM.
} 
assume that PSM is sufficiently widespread in the economy (or, equivalently, that demand for public sector output is not too high) so that in equilibrium the marginal workers and marginal managers have positive public service motivation. Consequently, an employee's wage in the public sector is lower than the wage paid by firms in the private sector. Likewise, the equilibrium price of public sector goods must be lower than the price of goods in the private sector. For otherwise, a given amount of production in the public sector would yield managers equal or higher revenue, lower wage cost, and higher motivational utility compared to the private sector, so that no one would be willing to become manager of a unit in the private sector.

These differences in wages and output prices between the public and the private sector have profound implications for the effect of managerial ability on a manager's payoff in the two sectors, and so for the sorting of people into public and private management. We show that, in any equilibrium where demand for public goods is not too high, the marginal return to managerial ability is higher in the private sector than in the public sector. Hence, the relative attractiveness of the public sector decreases in ability, and when the right tail of the ability distribution is sufficiently long, the most talented managers reside in the private sector. Furthermore, the least able managers may be found in the public sector.

A unique aspect of our analysis is that low remuneration for managers and workers in the public sector arises endogenously. While this implies that the public sector attracts managers with relatively low ability, it is the least costly way of producing a given amount of publicly provided goods. Hence, attempts to attract a more able managerial workforce to the public sector by increasing their remuneration to private sector levels are not efficient, neither from the perspective of a policy maker minimising cost of public goods provision nor for a social planner maximising social welfare.

The following simplified example highlights the main mechanism behind the negative selection of managerial talent into the public sector. Consider a set of entrepreneurs without personnel, who differ in their level of (nonnegative) PSM and in productive ability, and must choose between working in the public sector or in the private sector. When the output price is equal in both sectors, an entrepreneur's income is identical in both sectors, such that all entrepreneurs prefer to work in the public sector due to its intrinsic qualities (PSM). This causes the equilibrium output price in the public sector 
to drop below the private sector output price. The lower output price is particularly costly to highly able entrepreneurs, as they achieve high output levels. Hence, as the income gap between the public sector and the private sector widens with ability, the relative attractiveness of the public sector decreases in ability. Consequently, relatively many of the good entrepreneurs reside in the private sector.

Our theory is well in line with recent evidence on public-private wage differentials at the higher echelons as presented by Bargain and Melly (2008), using data for France. Whereas cross-sectional estimates show substantial negative public sector wage premiums at the top of the wage distribution, these are much smaller when controlling for individual fixed effects. Bargain and Melly (2008) interpret this as: "At the top of the wage distribution, agents with the highest wage potential ... have self-selected in the private sector" (p.13). ${ }^{6}$

Our theory is also applicable beyond the public-private setting. For instance, many non-profit organisations are regarded as intrinsically attractive (cf. Preston, 1989; Rose-Ackerman, 1996). Most studies find a negative wage differential in the non-profit sector (Mocan and Tekin (2002) is a notable exception), and some attribute this finding partially to selection effects. For instance, Weisbrod (1983) finds a 20\% wage penalty for lawyers in non-profit 'public interest' firms, while Goddeeris (1988) argues that a large part of this differential is driven by selection. In line with our theory, Preston (1989) finds that the non-profit wage penalty is higher for managers and professionals than for sales and clerical workers, and her results support the hypothesis that the wage difference is partially driven by selection. Lastly, Roomkin and Weisbrod (1999) show that top executives in for-profit hospitals receive both larger total income and larger incentive pay than their counterparts in non-profit hospitals, but the difference is smaller at lower levels in the hierarchy.

We proceed as follows. The next section discusses related literature. Section 3 describes the model and Section 4 analyses the optimal choices of

\footnotetext{
${ }^{6}$ Earlier papers on public-private wage differentials also find public sector wage penalties at the top of the wage distribution (Poterba and Rueben, 1994; Disney and Gosling, 1998; Melly, 2005), but cannot account for endogenous selection effects. At the bottom of the wage distribution, empirical studies often find wage premia rather than penalties. One reason - outside the scope of our theory - for this may be that wage negotiators in the public sector are less tough than in the private sector, as in e.g. Haskel and Szymanski (1993). As long as wage premia at the bottom are limited, all of our results go through.
} 
workers and managers in the two sectors. Section 5 describes individuals' choice between the four jobs in our economy, for any relative wage and price level at which production takes place in both sectors. Section 6 characterises the equilibrium. Section 7 concludes.

\section{Related Literature}

Our paper builds on the literature on compensating wage differentials. The theory of equalizing differences developed by Rosen (1974) asserts that in a competitive labour market, marginal workers' valuation of job attributes is reflected in compensating wage differentials (see also Brown, 1980; Rosen, 1986). Selection effects complicate the empirical estimation of these compensating wage differentials, see e.g. Goddeeris (1988) and Hwang et al. (1992). The reason is that wage differentials may also arise from unobserved differences in workers' ability, which in turn may be related to job attributes, e.g. because a worker's valuation of job attributes depends on his income (Goddeeris, 1988; Krueger and Summers, 1988; Gibbons and Katz, 1992). Recent work using matched employee-employer data establishes that inter-industry wage differentials are largely explained by these unobserved ability differences (Abowd et al., 1999; Goux and Maurin, 1999). In line with these findings, the public-private earnings differential for managers that arises in our framework is partly a 'true' compensating earnings differential and partly caused by selection, where selection arises endogenously from the adjustment in prices and wages to differences in sector's job attributes.

The recent literature in economics on intrinsic motivation studies the assignment of differently motivated workers to jobs that vary in intrinsic qualities (Handy and Katz, 1998; Dixit, 2002; Besley and Ghatak, 2005; Francois, 2007; Prendergast, 2007; Delfgaauw and Dur, 2007, 2008). A key prediction of this literature is relatively low pay and weak monetary incentives in jobs with high intrinsic qualities, as these lead to self-selection of job applicants with high motivation (on average). ${ }^{7}$ We contribute to this literature by providing the first general equilibrium model of the selfselection of people who differ in intrinsic motivation and in task-specific

\footnotetext{
${ }^{7}$ Boyne (2002) reviews evidence in the public administration and management literature on differences between private and public organisations, which suggests that public managers tend to place more emphasis on public service and less on remuneration than private managers.
} 
ability into jobs that differ in intrinsic qualities and in tasks.

Other papers have studied the assignment of people with heterogenous ability to different hierarchical levels in firms. Rosen (1982) and Waldman (1984) show that if managerial and subordinate inputs are complementary in production, such that performance at the top affects productivity in lower hierarchical levels, market forces assign the best-performing individuals to the top of large organisations. Output, labour input, firm size, and managerial rewards all increase more than proportionally in managerial ability. Later studies take a dynamic approach by incorporating learning and/or human capital acquisition in order to explain promotion and wage growth patterns; see Gibbons and Waldman (1999) for an overview and Costrell and Loury (2004), Gibbons and Waldman (2006), and Kwon (2006) for recent contributions. In contrast to these papers, we employ a static model with only two hierarchical levels; our contribution lies in relaxing the assumption that all firms are (ex ante) identical. We show that heterogenous preferences for non-pecuniary job aspects that differ across firms create differences in the return to managerial ability across firms, and thereby affect job assignment.

\section{The Model}

We consider a perfectly competitive economy consisting of two sectors $s \in$ $[g, k]$ : the public sector $(g)$ and the private sector $(k)$. In both sectors, production takes place in organisations, each consisting of a manager and a number of employees. Output produced in sector $s$ is sold at price $p^{s}$ per unit. Throughout, we assume that demand for products and, hence, prices are such that production takes place in both sectors of the economy. We think of demand for publicly provided goods as stemming from a political process, which we treat as exogenous. In most of the analysis, we shall assume that this demand for publicly provided goods triggers market supply. Proposition 3, however, will generalise our results to the case where a social planner or a policy maker who aims to minimise the cost of public goods provision assigns people to jobs and can differentiate remuneration for similar jobs. For simplicity, we assume that taxes are nondistortionary. This allows us to ignore taxation throughout the analysis.

All $N$ individuals in the economy choose between four occupations: 1 ) worker in the private sector; 2) worker in the public sector; 3) manager in the 
private sector; 4) manager in the public sector. Individuals can also decide to remain non-employed. In the latter case, they obtain outside option utility $U_{0}$.

People are heterogenous in two dimensions. First, they differ in managerial ability $\alpha_{i} \in[0, \bar{\alpha}]$. The implications of $\alpha_{i}$ for an individual's productivity and payoff will become clear from our description of production technology below. Second, people differ in their intrinsic preference for working in the public sector relative to working in the private sector. We assume that this intrinsic utility only depends on the choice of sector, not on occupation or effort. In the Concluding Remarks, we discuss the case where intrinsic utility is also dependent on effort choice. Let $\gamma_{i}^{s}$ denote individual $i$ 's intrinsic utility derived from working in sector $s$. For convenience, we normalise individuals' intrinsic utility from working in the private sector to zero: $\gamma_{i}^{k}=0$ for all $i$. This implies that $\gamma_{i}^{g}$ describes an individual's relative preference for working in the public sector, which we refer to as 'public service motivation' (PSM). Generally, people may intrinsically prefer to work in either sector; that is, an individual's $\gamma_{i}^{g}$ can be positive or negative. We focus on the case where PSM is sufficiently prevalent (or, equivalently, where demand for publicly provided goods is sufficiently small) so that in equilibrium the marginal managers and employees have positive public service motivation. Without further loss of generality, this allows us to reduce the type space to non-negative PSM: $\gamma_{i}^{g} \in[0, \bar{\gamma}]$. The density of the joint distribution of $\alpha_{i}$ and $\gamma_{i}^{g}$ is described by $f(\alpha, \gamma)>0$ over its support $[0, \bar{\alpha}] \times[0, \bar{\gamma}]$ and zero elsewhere.

Production technology is identical across sectors. Two types of tasks are performed in a unit: managerial tasks and non-managerial tasks. Let $m_{i, j}^{s}$ and $e_{i, j}^{s}$ be the amount of effort exerted on managerial and non-managerial tasks, respectively, by individual $i$ in occupation $j \in[w, m]$ when working in sector $s$, where subscript $j=w$ denotes worker and $j=m$ denotes manager. We assume that workers only perform non-managerial tasks, $m_{i, w}^{s}=0$ for all $i$ and $s$, while a manager can provide effort on both tasks. We thus allow managers to perform multiple tasks, which - as we shall see - managers find in their interest unless their managerial ability is sufficiently high. Let $n_{i}^{s}$ denote the number of workers employed by manager $i$ in sector $s$. Production 
$q$ in this manager's unit is described by:

$$
q(E, M)=q\left(n_{i}^{s} e_{w}^{s}+e_{i, m}^{s}, \alpha_{i} m_{i, m}^{s}\right)
$$

Production thus depends on the total amount of effort spent on non-managerial tasks, $E=n_{i}^{s} e_{w}^{s}+e_{i, m}^{s}$, and on effective managerial effort, $M=\alpha_{i} m_{i, m}^{s} \cdot{ }^{8}$

We make the following assumptions about the production function. First, to generate production in a unit, both managerial and non-managerial tasks must be performed, $q(E, 0)=q(0, M)=0$. Second, a unit's production is concave in both elements: $q_{E}>0, q_{E E}<0, q_{M}>0, q_{M M}<0$, where, throughout the paper, subscripts to functions denote partial derivatives. Third, we assume that effective managerial effort increases the marginal productivity of effort on non-managerial tasks: $q_{E M}>0$. By Young's theorem, this assumption also implies that the marginal return to management is higher in units where more non-managerial effort is being provided $\left(q_{M E}>0\right) .{ }^{9}$ Further note that (1) implies that, all else equal, the productivity of managerial effort $m_{i, m}^{s}$ increases in managerial ability $\alpha_{i}$. We thus assume that for a given level of managerial effort, more able managers establish more productive management practices than less able managers. Note also that, for given $M$, an individual's managerial ability $\alpha_{i}$ is irrelevant for his productivity in performing non-managerial tasks. This is innocuous: all results carry over when ability has a positive but limited effect on the productivity of effort spent on non-managerial tasks. We make the following additional assumption on the shape of the production function:

$$
q_{M}+\alpha_{i} m_{i, m}^{s}\left[q_{M M}-\frac{q_{E M}^{2}}{q_{E E}}\right]>0
$$

where we have suppressed the arguments of the derivatives of the production function for clarity. Assumption (2) assures that $q(E, M)$ is not too concave, so that more able managers find it worthwhile to put in more managerial effort $m_{i, m}^{s}$ than less able managers, see Proposition $1 .{ }^{10}$ Lastly, we

\footnotetext{
${ }^{8}$ Here, we use the result, derived in Section 4.1, that in equilibrium all workers in sector $s$ exert the same level of effort. This allows us to write the total amount of effort exerted by workers in the unit as $n_{i}^{s} e_{w}^{s}$.

${ }^{9}$ The complementarity between managerial ability and non-managerial input is also an important feature in Rosen (1982).

${ }^{10}$ This is a mild restriction. It allows, for instance, for Cobb-Douglas and logarithmic production functions.
} 
assume that the third derivatives of $q(E, M)$ are not too large; the proof of Proposition 2 contains the exact restriction.

Individuals derive utility from their income $y$ and from their intrinsic preference for working in a sector $\gamma_{i}^{s}$. They derive disutility from exerting effort. We assume that an individual's cost of effort depends on the sum of his effort spent on managerial and non-managerial tasks. Hence, utility of individual $i$ working in sector $s$ in occupation $j$ is given by:

$$
U_{i, j}^{s}=y_{i, j}^{s}+\gamma_{i}^{s}-c\left(e_{i, j}^{s}+m_{i, j}^{s}\right) .
$$

As usual, the cost of effort are increasing and convex: $c_{e}=c_{m}>0, c_{e e}=$ $c_{m m}=c_{e m}>0$.

Managers pay workers a wage per unit of effort. Allowing firms to pay a base salary or, more generally, to offer non-linear wage schemes does not change any of our results, because competition for workers rules out rent extraction and risk neutrality implies that there is no trade-off between incentives and risk-sharing. ${ }^{11}$ The wage per unit of effort in sector $s$ equals $w^{s}$. In equilibrium, wages are such that in both sectors, supply of and demand for workers are equal. The income of a worker employed by a firm in sector $s$ equals

$$
y_{i, w}^{s}=w^{s} e_{i, w}^{s} .
$$

For convenience and without loss of generality, we assume that the distribution of individuals is such that at the market-clearing wage levels some individuals end up nonemployed. This assumption requires that $U_{0} \geq 0$ and that $f(\alpha, \gamma)$ has sufficient mass in the vicinity of $(0,0) .{ }^{12}$

Managers are the residual claimants of their unit. Hence, a manager's income equals the revenues of his unit minus costs. The income of manager $i$ in sector $s$ who employs $n_{i}^{s}$ workers equals:

$$
y_{i, m}^{s}=p^{s} q\left(n_{i}^{s} e_{w}^{s}+e_{i, m}^{s}, \alpha_{i} m_{i, m}^{s}\right)-w^{s} n_{i}^{s} e_{w}^{s}-h,
$$

\footnotetext{
${ }^{11}$ We abstract from explicit moral hazard issues. One interpretation of the complementarity between managerial and non-managerial effort is that good managers are better in channeling employees' efforts towards the most productive tasks.

${ }^{12}$ Note that $U_{0}<0$ implies full employment because, in that case, individuals would always weakly prefer having a job involving no effort and paying a wage equal to $U_{0}<0$ to being nonemployed. That is, people would be willing to pay a firm to exit nonemployment, which results in full employment in equilibrium.
} 
where $h$ is a fixed management cost. These cost include, among others, the cost of setting up a unit and overhead costs. We assume that $h$ is sufficiently high such that there are no individuals who prefer to become 'manager' of a unit without any employees $\left(n_{i}^{s}=0\right)$ rather than becoming either employee or manager of a unit with employees.

\section{Behaviour of Managers and Workers}

\subsection{Workers' effort and wages}

As workers do not engage in managerial tasks, the only effort decision for workers is how much effort to put into the non-managerial tasks. Substituting income (4) into the utility function (3) and maximising with respect to $e_{w}^{s}$, we obtain the following first-order condition for optimal effort:

$$
w^{s}-c_{e}\left(e_{w}^{s}\right)=0
$$

Note that we have suppressed subscript $i$, since optimal effort does neither depend on $\alpha_{i}$ nor on $\gamma_{i}^{g}$. The second-order condition is satisfied by the convexity of the cost of effort function. Let $\tilde{e}_{w}^{s}$ be the solution to (6) for workers in sector $s$. The utility of workers in the private sector and in the public sector is given by, respectively:

$$
\begin{gathered}
U_{w}^{k}=w^{k} \tilde{e}_{w}^{k}-c\left(\tilde{e}_{w}^{k}\right), \\
U_{i, w}^{g}=w^{g} \tilde{e}_{w}^{g}+\gamma_{i}^{g}-c\left(\tilde{e}_{w}^{g}\right) .
\end{gathered}
$$

Note that private sector workers' utility is independent of type. Hence, given that in equilibrium some individuals are nonemployed and receive outside option utility $U_{0}$, competition ensures that workers in the private sector achieve utility $U_{0}$. Suppose, instead, that the utility of workers in the private sector would exceed $U_{0}$. Then, the nonemployed would underbid the employed workers. Similarly, if workers' utility would be lower than $U_{0}$, then nobody would prefer being a worker in the private sector to being nonemployed, resulting in an increase in the private sector wage. Hence, wage $w^{k}$ is determined by the participation constraint:

$$
w^{k} \tilde{e}_{w}^{k}-c\left(\tilde{e}_{w}^{k}\right)=U_{0} .
$$


Utility of public sector workers is independent of $\alpha_{i}$ and increasing in $\gamma_{i}^{g}$. Hence, except for the marginal workers, workers in the public sector earn a rent. The identity of the marginal workers follows from equating (7) and (8):

$$
w^{g} \tilde{e}_{w}^{g}+\widehat{\gamma}-c\left(\tilde{e}_{w}^{g}\right)=w^{k} \tilde{e}_{w}^{k}-c\left(\tilde{e}_{w}^{k}\right)=U_{0}
$$

where $\widehat{\gamma}$ denotes the level of $\gamma_{i}^{g}$ at which individuals are indifferent between working in the public and the private sector. Totally differentiating (10) and using (6) we find a negative relation between $w^{g}$ and $\widehat{\gamma}$ and a positive relation between $w^{k}$ and $\widehat{\gamma}$ :

$$
\frac{d \widehat{\gamma}}{d w^{g}}=-\frac{1}{\tilde{e}_{w}^{g}}<0 ; \quad \frac{d \widehat{\gamma}}{d w^{k}}=\frac{1}{\tilde{e}_{w}^{k}}>0 .
$$

Intuitively, an increase in the wage in the public sector attracts some workers from the private sector. These have a lower intrinsic utility than workers who were already employed in the public sector (i.e., $\widehat{\gamma}$ reduces). Likewise, when working in the private sector becomes more rewarding, some public sector workers move to the private sector, as their intrinsic utility no longer makes up for the difference in wages. Hence, the intrinsic utility of the marginal worker $\widehat{\gamma}$ increases.

Using (10) and (6), we find that if $w^{g}=w^{k}$, then $\widehat{\gamma}=0$. Since $\gamma_{i}^{g} \in$ $[0, \bar{\gamma}]$, it follows that with uniform wages across sectors all individuals prefer working in the public sector to working in the private sector. Hence, using (11), it follows that in any equilibrium where a strictly positive number of people prefer being a worker in the private sector to being a worker in the public sector, it must hold that $w^{k}>w^{g}$. Thus, there is a negative compensating wage differential in the public sector as the marginal public sector worker derives positive intrinsic utility from working in the public sector. Using (6), a consequence of $w^{k}>w^{g}$ is that workers in the private sector put in more effort than workers in the public sector: $\tilde{e}_{w}^{k}>\tilde{e}_{w}^{g}$. Clearly, the negative compensating wage differential dilutes financial incentives to exert effort in the public sector. Lemma 1 summarises these findings.

Lemma 1 There is a single level of $\gamma_{i}^{g}$, denoted by $\widehat{\gamma}$, at which individuals are indifferent between working in the public and the private sector. Individuals with $\gamma_{i}^{g}>\widehat{\gamma}$ strictly prefer working in the public sector to working in the private sector, and individuals with $\gamma_{i}^{g}<\hat{\gamma}$ strictly prefer working in the 
private sector. $\widehat{\gamma}$ decreases with the public sector wage $w^{g}$ and increases with the private sector wage $w^{k}$. For any $\widehat{\gamma}>0$, it must hold that $w^{k}>w^{g}$. This negative compensating wage differential implies that workers in the private sector exert more effort than workers in the public sector: $\tilde{e}_{w}^{k}>\tilde{e}_{w}^{g}$.

\subsection{Managers' effort, employment choice, and profits}

Managers choose how many workers to hire and how much effort to spend on managerial and non-managerial tasks, taking the wage $w^{s}$ and the price $p^{s}$ as given. Substituting manager's income (5) into utility function (3) and maximising with respect to $m_{i, m}^{s}, e_{i, m}^{s}$, and $n_{i}^{s}$, we obtain the following first-order conditions:

$$
\begin{gathered}
\alpha_{i} p^{s} q_{M}\left(n_{i}^{s} \tilde{e}_{w}^{s}+e_{i, m}^{s}, \alpha_{i} m_{i, m}^{s}\right)-c_{m}\left(e_{i, m}^{s}+m_{i, m}^{s}\right)=0, \\
p^{s} q_{E}\left(n_{i}^{s} \tilde{e}_{w}^{s}+e_{i, m}^{s}, \alpha_{i} m_{i, m}^{s}\right)-c_{e}\left(e_{i, m}^{s}+m_{i, m}^{s}\right)=0, \\
p^{s} q_{E}\left(n_{i}^{s} \tilde{e}_{w}^{s}+e_{i, m}^{s}, \alpha_{i} m_{i, m}^{s}\right)-w^{s}=0 .
\end{gathered}
$$

In Appendix A.1, we show that the second-order conditions for a global maximum are satisfied if for all $m_{i, m}^{s}, e_{i, m}^{s}$, and $n_{i}^{s}$ :

$$
q_{M M} q_{E E}-q_{E M}^{2}>0
$$

Let $\tilde{m}_{i, m}^{s}, \tilde{e}_{i, m}^{s}$, and $\tilde{n}_{i}^{s}$ be the joint solution to (12), (13), and (14) for manager $i$ in sector $s$. Note that this solution does not depend on $\gamma_{i}^{s}$. The utility of private sector managers and public sector managers is given by, respectively:

$$
\begin{gathered}
U_{i, m}^{k}=p^{k} q\left(\tilde{n}_{i}^{k} \tilde{e}_{w}^{k}+\tilde{e}_{i, m}^{k}, \alpha_{i} \tilde{m}_{i, m}^{k}\right)-\tilde{n}_{i}^{k} w^{k} \tilde{e}_{w}^{k}-c\left(\tilde{m}_{i, m}^{k}+\tilde{e}_{i, m}^{k}\right)-h, \\
U_{i, m}^{g}=p^{g} q\left(\tilde{n}_{i}^{g} \tilde{e}_{w}^{g}+\tilde{e}_{i, m}^{g}, \alpha_{i} \tilde{m}_{i, m}^{g}\right)-\tilde{n}_{i}^{g} w^{g} \tilde{e}_{w}^{g}+\gamma_{i}^{g}-c\left(\tilde{m}_{i, m}^{g}+\tilde{e}_{i, m}^{g}\right)-h .
\end{gathered}
$$

Combining (13) and (14) and the first-order condition for optimal effort of workers (6), we find that $\tilde{e}_{i, m}^{s}+\tilde{m}_{i, m}^{s}=\tilde{e}_{w}^{s}$. Hence, managers in sector $s$ exert the same amount of effort as workers in the same sector. Since private sector workers put in more effort than public sector workers (see Lemma 1), it follows that private sector managers put in more effort than public sector managers. 
Proposition 1 describes the comparative static effects of managerial ability $\alpha_{i}$, the wage $w^{s}$, and the product price $p^{s}$ on managers' decisions.

Proposition 1 If condition (2) on the concavity of the production function is satisfied, then it holds that in a given sector managers with higher ability $\alpha_{i}$ optimally exert more managerial effort (higher $\tilde{m}_{i, m}^{s}$ ), exert less nonmanagerial effort (lower $\tilde{e}_{i, m}^{s}$ ), employ more workers (higher $\tilde{n}_{i}^{s}$ ), and evoke higher total nonmanagerial effort $\left(\tilde{n}_{i}^{s} \tilde{e}_{w}^{s}+\tilde{e}_{i, m}^{s}\right)$. Managers with higher ability achieve higher production, higher income, and higher utility. An increase in the price $p^{s}$ or a decrease in the wage $w^{s}$ induces managers to increase managerial effort $\tilde{m}_{i, m}^{s}$, decrease their nonmanagerial effort $\tilde{e}_{i, m}^{s}$, and increase employment $\tilde{n}_{i}^{s}$ and total nonmanagerial effort $\tilde{n}_{i}^{s} \tilde{e}_{w}^{s}+\tilde{e}_{i, m}^{s}$.

\section{Proof. See Appendix A.2.}

Proposition 1 shows that better managers spend more effort on managing their organisation and less effort on non-managerial tasks than less talented managers. Better managers also run bigger organisations, earn higher income, and achieve higher utility. Clearly, the complementarity between managerial and non-managerial tasks makes it attractive for highly able managers to hire many workers and increase their productivity through high managerial effort. High managerial effort implies high marginal cost of effort, and so highly able managers exert little non-managerial effort themselves. ${ }^{13}$ A higher product price induces managers to expand production by increasing employment and exerting more managerial effort, which comes at the expense of the manager's non-managerial effort. Conversely, higher wages result in lower employment, less management effort, and a higher level of non-managerial effort provided by the manager himself.

When wages and/or prices differ between sectors, managers in the public sector act differently from managers with the same ability in the private sector. As noted before, the lower wage in the public sector makes that

\footnotetext{
${ }^{13}$ Highly able managers may optimally decide to only engage in managerial tasks and to set $e_{i, m}^{s}=0$. This occurs when at the solution to first-order condition (12) with $e_{i, m}^{s}=0$, we have that $c_{m}\left(m_{i, m}^{s}\right)>w^{s}$. Generally, in equilibrium, the marginal managers in both sectors optimally choose $e_{i, m}^{s}>0$, unless $h$ is very high. We therefore focus in the following on the case where the marginal managers perform multiple tasks. In Appendix A.3, we show that the comparative static effects of $\alpha_{i}$ on $m_{i, m}^{s}$ and $n_{i}^{s}$ at levels of $\alpha_{i}$ where managers optimally set $e_{i, m}^{s}=0$ have the same sign but are generally smaller in magnitude. Intuitively, $e_{i, m}^{s}=0$ implies that the marginal cost of $m_{i, m}^{s}$ cannot be reduced by further decreasing $e_{i, m}^{s}$.
} 
managers exert less effort in total when managing a public organisation. The following lemma describes several other differences between managers' decisions in the two sectors.

Lemma 2 Comparing organisations led by managers with the same ability $\alpha_{i}$ across sectors, it holds that in the sector where $\frac{w^{s}}{p^{s}}$ is higher, managerial effort $\tilde{m}_{i, m}^{s}$, total effort on non-managerial tasks $\tilde{n}_{i}^{s} \tilde{e}_{w}^{s}+\tilde{e}_{i, m}^{s}$, and production are lower.

Proof. Combining first-order conditions (12), (13), and (14), we obtain

$$
\alpha_{i} q_{M}\left(n_{i}^{s} \tilde{e}_{w}^{s}+e_{i, m}^{s}, \alpha_{i} m_{i, m}^{s}\right)=q_{E}\left(n_{i}^{s} \tilde{e}_{w}^{s}+e_{i, m}^{s}, \alpha_{i} m_{i, m}^{s}\right)=\frac{w^{s}}{p^{s}} .
$$

Hence, for a given managerial ability $\alpha_{i}$, both $q_{M}\left(n_{i}^{s} \tilde{e}_{w}^{s}+e_{i, m}^{s}, \alpha_{i} m_{i, m}^{s}\right)$ and $q_{E}\left(n_{i}^{s} \tilde{e}_{w}^{s}+e_{i, m}^{s}, \alpha_{i} m_{i, m}^{s}\right)$ increase in $\frac{w^{s}}{p^{s}}$. By second-order condition (15), this dual increase can only be attained through a reduction in both $n_{i}^{s} \tilde{e}_{w}^{s}+e_{i, m}^{s}$ and $m_{i, m}^{s}$. Since $q_{E}<0$ and $q_{M}<0$, these reductions negatively affect production.

It follows from Lemma 2 that if $\frac{w^{g}}{p^{g}}=\frac{w^{k}}{p^{k}}$, managers with equal ability exert the same level of managerial effort in both sectors and evoke similar total effort on non-managerial tasks. Note, however, that even if the wage-price ratio is identical across sectors, the lower wage in the public sector implies that managers in public organisations exert less effort on nonmanagerial tasks themselves and rely more on effort exerted by their workers. Intuitively, if it is less expensive to hire workers for the non-managerial tasks, it pays for a manager to exert less effort on these tasks himself. The following section will show that not only wages, but also prices are lower in the public sector. As it turns out, whether the wage-price ratio is higher or lower in the public sector critically depends on the exact distribution of management talent and public service motivation in the population.

\section{Occupational Choice}

Individuals in our economy can choose between four occupations and the outside option. Since the equilibrium payoff of a private sector worker equals the outside option utility for all individuals (see (9)), people effectively face 
four different options. ${ }^{14}$ We proceed by making pairwise comparisons between these options, to establish which types are indifferent between any two occupations. Graphing the six indifference lines that arise in the $(\alpha, \gamma)$ plane characterises the equilibrium allocation of individuals' types to jobs for given wages and prices. In the next section, we shall study the equilibrium levels of wages and prices in the two sectors.

\section{Indifference line 1: Private worker / private manager}

When people must choose between becoming worker or manager in the private sector, their motivation to work in the public sector $\gamma_{i}^{g}$ is irrelevant. This implies that the level of managerial ability at which people are indifferent between becoming private sector worker and private sector manager does not depend on $\gamma_{i}^{g}$. Lemma 3 follows.

Lemma 3 There is a single value of managerial ability $\alpha_{i}$ at which people are indifferent between working in a private sector organisation and managing a private sector organisation. Individuals with higher ability prefer to become manager, people with lower ability prefer to become worker. Denote this level of ability by $\widehat{\alpha}^{k}$. It is implicitly described by

$$
p^{k} q\left(\tilde{n}_{i}^{k} \tilde{e}_{w}^{k}+\tilde{e}_{i, m}^{k}, \widehat{\alpha}^{k} \tilde{m}_{i, m}^{k}\right)-\left(\tilde{n}_{i}^{k}+1\right) w^{k} \tilde{e}_{w}^{k}-h=0 .
$$

$\widehat{\alpha}^{k}$ is strictly positive and independent of $\gamma_{i}^{g}$.

Proof. The first part follows from observing that private sector workers' utility (7) is constant in both $\gamma_{i}^{g}$ and $\alpha_{i}$ whereas private sector managers' utility (16) is constant in $\gamma_{i}^{g}$ and increasing in $\alpha_{i}$ :

$$
\frac{d U_{i, m}^{k}}{d \alpha_{i}}=\tilde{m}_{i, m}^{k} p^{k} q_{M}\left(\tilde{n}_{i}^{k} \tilde{e}_{w}^{k}+\tilde{e}_{i, m}^{k}, \alpha_{i} \tilde{m}_{i, m}^{k}\right)>0
$$

where the effects through changes in $\tilde{m}_{i, m}^{k}, \tilde{e}_{i, m}^{k}$, and $\tilde{n}_{i}^{k}$ are zero by the envelop theorem. Equation (19) follows from setting (7) equal to (16), and using the result derived in Section 3 that $\tilde{m}_{i, m}^{k}+\tilde{e}_{i, m}^{k}=\tilde{e}_{w}^{k}$. From (19) it is

\footnotetext{
${ }^{14}$ Note that workers' utility and optimal effort are independent of their manager's type, and that managers do not care about workers' type. Hence, to make optimal choices, individuals only need information about wages, prices, and their own type. In other words, whether an individuals' public service motivation and/or managerial ability is public or private information is irrelevant for our results.
} 
clear that $\widehat{\alpha}^{k}$ is independent of $\gamma_{i}^{g}$. Further, since $q(E, 0)=0, h>0$, and $U_{0}>0$ (implying that the left-hand side of (19) is strictly negative when $\alpha=0$ ), equation (20) implies that $\widehat{\alpha}^{k}$ is strictly positive.

Managerial ability affects the profitability of running an organisation, with better managers making more money. The assumption that $q(E, 0)=0$ implies that individuals with $\alpha_{i}=0$ always prefer being an employee over being a manager. Hence, $\widehat{\alpha}^{k}>0$. Using (19), it is also easily verified that a higher price $p^{k}$ and a lower management cost $h$ makes a management position in the private sector more attractive $\left(\widehat{\alpha}^{k}\right.$ decreases $)$. A higher wage $w^{k}$ increases $\widehat{\alpha}^{k}$ for two reasons: it increases income when opting for a private sector job and increases wage costs when running a private sector organisation.

\section{Indifference line 2: Private worker / public worker}

Lemma 1 has established that there is a single level of intrinsic utility $\widehat{\gamma}$ at which individuals are indifferent between working in a private organisation and working in a public organisation. Rewriting (10), $\widehat{\gamma}$ is given by:

$$
\widehat{\gamma}=U_{0}+c\left(\tilde{e}_{w}^{g}\right)-w^{g} \tilde{e}_{w}^{g}
$$

Clearly, $\widehat{\gamma}$ is independent of $\alpha_{i}$. Lemma 1 has also already shown that $\widehat{\gamma}$ increases with the wage differential between the private sector and the public sector.

\section{Indifference line 3: Private manager / public worker}

An individual $i$ is indifferent between working in the public sector and managing an organisation in the private sector when (8) equals (16). Using (10), this can be written as:

$$
\gamma_{i}^{g}=p^{k} q\left(\tilde{n}_{i}^{k} \tilde{e}_{w}^{k}+\tilde{e}_{i, m}^{k}, \alpha_{i} \tilde{m}_{i, m}^{k}\right)-\tilde{n}_{i}^{k} w^{k} \tilde{e}_{w}^{k}-c\left(\tilde{m}_{i, m}^{k}+\tilde{e}_{i, m}^{k}\right)-h-\left[U_{0}-\widehat{\gamma}\right]
$$

Using (9), we find that if $\gamma_{i}^{g}=\widehat{\gamma}$, equation (22) reduces to (19). Hence, indifference line 3 runs through the intersection of line 1 and line $2\left(\widehat{\alpha}^{k}, \widehat{\gamma}\right)$. This makes sense: Individuals who are indifferent between being a private worker and being a private manager (line 1) and also between being a private worker and being a public worker (line 2), should also be indifferent between being a private manager and being a public worker (line 3 ). Totally 
differentiating equation (22) to $\gamma_{i}^{g}$ and $\alpha_{i}$ gives after some rewriting:

$$
\frac{d \gamma_{i}^{g}}{d \alpha_{i}}=\tilde{m}_{i, m}^{k} p^{k} q_{M}\left(\tilde{n}_{i}^{k} \tilde{e}_{w}^{k}+\tilde{e}_{i, m}^{k}, \alpha_{i} \tilde{m}_{i, m}^{k}\right)>0,
$$

where the effects through changes in $\tilde{m}_{i, m}^{k}, \tilde{e}_{i, m}^{k}$, and $\tilde{n}_{i}^{k}$ are zero by the envelop theorem. Hence, indifference line 3 is upward sloping in the $(\alpha, \gamma)$ plane: the higher an individual's $\alpha_{i}$, the higher the level of $\gamma_{i}^{g}$ necessary to make the individual prefer to become a worker in the public sector rather than manager in the private sector. The intuition is clear. Managerial ability increases the return to managing a private organisation. Therefore, highly able people only prefer being a worker in the public sector if their intrinsic utility is sufficiently high. Hence, working in the public sector is preferred by people with low ability and a large preference for the public sector, whereas talented individuals with little preference for the public sector prefer managing a private organisation. For individuals with $\alpha_{i}=0$, the first three terms in equation (22) are zero while the other terms are negative, implying that only a sufficiently negative taste for working in the public sector would make them indifferent. ${ }^{15}$ In other words, even people without a preference for working in the public sector must have a strictly positive level of managerial ability to favour the management position.

Just as an intermezzo, a graphical representation of the first three indifference lines in the $(\alpha, \gamma)$-plane is shown in Figure 1. Each line is bold in its relevant range and dashed when it is irrelevant. ${ }^{16}$ The exact positions of the lines depend on prices and wages in the sectors. Note that, while the $\alpha$-intercept and the slope of line 3 are unambiguously positive (see (22) and (23)), the exact shape of line 3 is ambiguous. This can be seen by differentiating (23):

$$
\frac{d^{2} \gamma_{i}^{g}}{d \alpha_{i}^{2}}=-p^{k} q_{M}\left(\frac{q_{M}+2 \alpha_{i} \tilde{m}_{i, m}^{k}\left[q_{M M}-\frac{q_{E M}^{2}}{q_{E E}}\right]}{\alpha_{i}^{2}\left[q_{M M}-\frac{q_{E M}^{2}}{q_{E E}}\right]}\right),
$$

\footnotetext{
${ }^{15}$ The first three terms are zero because a manager with $\alpha_{i}=0$ would optimally set $\tilde{n}_{i}^{k}=0$. The last terms $\left(-h-\left[U_{0}-\widehat{\gamma}\right]\right)$ are negative; this can be seen using $(21)$ and $(6)$ and noting that the convexity of the cost of effort function implies that $c\left(\tilde{e}_{w}^{g}\right)<c_{e}\left(\tilde{e}_{w}^{g}\right) \tilde{e}_{w}^{g}$.

${ }^{16}$ For instance, for values of $\alpha>\widehat{\alpha}^{k}$, line 2 is irrelevant: Since these individuals prefer being private manager to being private worker, the issue whether they prefer being private worker to being public worker is immaterial. The three additional indifference lines that we will discuss next render additional parts of the first three indifference lines irrelevant, see Figures $2 \mathrm{~A}$ and $2 \mathrm{~B}$ below.
} 
where we have suppressed the arguments of the derivatives of the production function for clarity. If (24) is positive (negative) for all $\alpha_{i} \geq 0$, then line 3 is convex (concave). Generally, we cannot say whether the expression in (24) is (always) positive or negative. ${ }^{17}$ Independent of the shape of line 3 , Figure 1 suggests that individuals with low managerial ability and little preference for the public sector prefer being a worker in the private sector (or being nonemployed). Workers in the public sector have relatively high levels of $\gamma_{i}^{g}$, and managers in the private sector have a relatively high $\alpha_{i}$. At first glance, one might expect that the managers in the public sector will be located in the upper-right part of Figure 1, having both high $\alpha_{i}$ and high $\gamma_{i}^{g}$. Generally, however, this is not the case, as we show now.

\section{Indifference line 4: Private manager / public manager}

An individual $i$ is indifferent between managing an organisation in the private sector and managing an organisation in the public sector when (16) equals (17), which can be written as:

$$
\begin{aligned}
\gamma_{i}^{g}= & p^{k} q\left(\tilde{n}_{i}^{k} \tilde{e}_{w}^{k}+\tilde{e}_{i, m}^{k}, \alpha_{i} \tilde{m}_{i, m}^{k}\right)-\tilde{n}_{i}^{k} w^{k} \tilde{e}_{w}^{k}-c\left(\tilde{m}_{i, m}^{k}+\tilde{e}_{i, m}^{k}\right) \\
& -\left[p^{g} q\left(\tilde{n}_{i}^{g} \tilde{e}_{w}^{g}+\tilde{e}_{i, m}^{g}, \alpha_{i} \tilde{m}_{i, m}^{g}\right)-\tilde{n}_{i}^{g} w^{g} \tilde{e}_{w}^{g}-c\left(\tilde{m}_{i, m}^{g}+\tilde{e}_{i, m}^{g}\right)\right] .
\end{aligned}
$$

Individuals with $\alpha_{i}=0$ do not generate income as a manager in either sector, and, hence, are indifferent between the two positions when they do not intrinsically prefer one sector over the other, i.e. when $\gamma_{i}^{g}=0$. Line 4 thus crosses the origin of the $(\alpha, \gamma)$-plane.

By Lemma 1, wage cost per unit of effort are lower in the public sector than in the private sector. Furthermore, our assumption that $\gamma_{i}^{g} \geq 0$ implies that all else equal, all people prefer to manage a public sector organisation over a private sector organisation. Lemma 4 states that to have a strictly positive number of people in the economy prefer the management job in the private sector to the management job in the public sector, $p^{k}$ must be larger than $p^{g}$.

Lemma 4 If $p^{k} \leq p^{g}$, all individuals with $\alpha_{i}>0$ and $\gamma_{i}^{g} \geq 0$ prefer being a manager in the public sector to being a manager in the private sector. Only when $p^{k}$ is sufficiently higher than $p^{g}$, a strictly positive number of people prefer managing a private organisation to managing a public organisation.

\footnotetext{
${ }^{17}$ Note that the condition for convexity of line 3 is stronger than condition (2).
} 
Proof. By Lemma 1, $w^{k}>w^{g}$ and so for a given level of labour inputs $n_{i} e_{w}$, total wage costs are lower in the public sector. Consider a manager with $\alpha_{i}>0$ who optimally sets $\tilde{m}_{i, m}^{k}, \tilde{e}_{i, m}^{k}$, and $\tilde{n}_{i}^{k}$ when running a private organisation. Suppose this manager would set the same levels of $m, e$, and $n$ in a public sector organisation, implying the same level of production. Then, if $p^{k} \leq p^{g}$, his payoff in the public sector is always higher because revenues are weakly higher, wage costs are strictly lower, and, since $\gamma_{i}^{g} \geq 0$, intrinsic utility is weakly higher (see (25)). Setting $m_{i, m}^{g}, e_{i, m}^{g}$, and $n_{i}^{g}$ at their optimal levels increases the payoff of being a public manager even further. Hence, if $p^{k} \leq p^{g}$, all individuals with $\alpha_{i}>0$ and $\gamma_{i}^{g} \geq 0$ prefer managing a public sector organisation to managing a private sector organisation. Increasing $p^{k}$ makes managing a private sector organisation more attractive, while leaving the payoff from managing a public organisation unchanged. Hence, the last part of the lemma follows.

Lemma 4 is crucial to our results. It shows that competition between differently motivated people for management positions in the two sectors results in a difference in output prices. In our case, the output in the public sector must be lower than in the private sector as the marginal manager derives positive non-pecuniary benefits from being active in the public sector. This effect is strengthened by the lower cost of labour in the public sector, which arises from positive public service motivation of the marginal worker. Only when $p^{k}$ is sufficiently higher than $p^{g}$, some managers generate sufficiently more revenue by running a private sector unit than by running a public sector unit so as to make up for the higher labour cost and (weakly) lower intrinsic utility.

This difference in prices has profound implications for the effect of management ability on a manager's payoff in the two sectors, and so for the sorting of highly able managers into the public sector. This can be seen by differentiating (25), which gives the slope of line 4 :

$$
\frac{d \gamma_{i}^{g}}{d \alpha_{i}}=p^{k} \tilde{m}_{i, m}^{k} q_{M}\left(\tilde{n}_{i}^{k} \tilde{e}_{w}^{k}+\tilde{e}_{i, m}^{k}, \alpha_{i} \tilde{m}_{i, m}^{k}\right)-p^{g} \tilde{m}_{i, m}^{g} q_{M}\left(\tilde{n}_{i}^{g} \tilde{e}_{w}^{g}+\tilde{e}_{i, m}^{g}, \alpha_{i} \tilde{m}_{i, m}^{g}\right) .
$$

The effect of $\alpha$ on managerial utility runs through an increase in production and, hence, revenue. ${ }^{18}$ As $p^{k}>p^{g}$, a given increase in production is more

\footnotetext{
${ }^{18}$ All effects through employment, management effort, and the manager's nonmanagerial effort are zero by the envelop theorem.
} 
valuable in the private sector. Yet, the slope of (25) also depends on how much additional production an increase in $\alpha$ generates, which might be higher in the public sector. Proposition 2 shows that, in the relevant case where a strictly positive number of people prefer to become manager in the private sector, revenues rise faster with ability in the private sector than in the public sector, and hence line 4 is upward-sloping in the relevant area.

Proposition 2 Given that some individuals prefer to be manager in the public sector and others to be manager in the private sector, line 4 is upward sloping for all $\alpha_{i}>0$ and $\gamma_{i}^{g} \geq 0$.

Proof. As $w^{k}>w^{g}$, it follows from (18) that for a given level of $\alpha_{i}$, $p^{k} q_{M}\left(\tilde{n}_{i}^{k} \tilde{e}_{w}^{k}+\tilde{e}_{i, m}^{k}, \alpha_{i} \tilde{m}_{i, m}^{k}\right)>p^{g} q_{M}\left(\tilde{n}_{i}^{g} \tilde{e}_{w}^{g}+\tilde{e}_{i, m}^{g}, \alpha_{i} \tilde{m}_{i, m}^{g}\right)$. By Lemma 2, if $\frac{w^{k}}{p^{k}} \leq \frac{w^{g}}{p^{g}}$ we have that $\tilde{m}_{i, m}^{k} \geq \tilde{m}_{i, m}^{g}$. Hence, if $\frac{w^{k}}{p^{k}} \leq \frac{w^{g}}{p^{g}},(26)$ is positive, implying that line 4 is upward sloping for all $\alpha_{i}$. However, if $\frac{w^{k}}{p^{k}}>\frac{w^{g}}{p^{g}}$, we have that $\tilde{m}_{i, m}^{k}<\tilde{m}_{i, m}^{g}$, implying that (26) can be negative. In Appendix A.4, we prove that if (26) is negative for some range of $\alpha_{i}$, it must be that (25) is U-shaped in order to have managers in the private sector. As line 4 starts in the origin, this implies that for levels of $\alpha_{i}>0$ at which (25) is non-negative, the slope of line 4 is positive.

The interpretation behind this result is straightforward. Lemma 4 showed that, as a result of lower wage cost and higher intrinsic utility in the public sector, the equilibrium price of public sector goods is lower than the price of private sector goods. This creates a difference in managerial income between the two sectors that is increasing in ability. In other words, the higher output price in the private sector is particularly attractive to highly able managers, as they run large organisations producing lots of output. This effect is reinforced when managers in the private sector exert more managerial effort compared to equally able managers in the public sector, as this implies that output rises faster with managerial ability in the private sector than in the public sector. However, it cannot be ruled out that for given ability managerial effort is higher in the public sector than in the private sector $\left(\tilde{m}_{i, m}^{g}>\tilde{m}_{i, m}^{k}\right)$, as we have seen in Lemma 2 . When $\tilde{m}_{i, m}^{g}$ is sufficiently larger than $\tilde{m}_{i, m}^{k}$, it is possible that an increase in ability yields so much more additional production in the public sector that despite the lower price level, revenue in the public sector rises more with ability than in 
the private sector. In this case, however, the proof of Proposition 2 shows that there are no managers in the private sector at all, unless line 4 slopes upward for sufficiently high values of $\alpha_{i}$. Hence, Proposition 2 shows that if equilibrium wages and prices are such that production takes place in both sectors of the economy, line 4 has an upward slope in the relevant area. In other words, the return to managerial ability is higher for managers in the private sector than for managers in the public sector. ${ }^{19}$

Lastly, comparing (26) with (23), we find that for any value of $\alpha_{i}>0$, the slope of indifference line 3 is larger than the slope of line 4 . Moreover, comparing (25) with (22), it follows that at $\alpha_{i}=0$ line 4 lies above line 3. These two results imply that there is only one point of intersection between line 3 and line 4.

\section{Indifference line 5: Public worker / public manager}

Next consider the choice between working in or managing an organisation in the public sector. As the intrinsic utility people derive from being active in the public sector is independent of their occupation, $\gamma_{i}^{g}$ has no effect on this choice. Only managerial ability matters. Lemma 5 follows.

Lemma 5 There is a single value of managerial ability $\alpha_{i}$ at which people are indifferent between working in a public sector organisation and managing a public sector organisation. Individuals with higher ability prefer to become manager, people with lower ability prefer to become worker. Denote this level of ability by $\widehat{\alpha}^{g}$. It is implicitly described by

$$
p^{g} q\left(\tilde{n}_{i}^{g} \tilde{e}_{w}^{g}+\tilde{e}_{i, m}^{g}, \widehat{\alpha}^{g} \tilde{m}_{i, m}^{g}\right)-\left[\tilde{n}_{i}^{g}+1\right] w^{g} \tilde{e}_{w}^{g}-h=0 .
$$

$\widehat{\alpha}^{g}$ is positive and independent of $\gamma_{i}^{g}$.

Proof. The first part follows from i) observing that workers' utility (8) and managers' utility (17) are increasing in $\gamma_{i}^{g}$ with the same slope; ii) observing that workers' utility (8) is constant in $\alpha_{i}$ whereas managers' utility (17) is

\footnotetext{
${ }^{19}$ If we would allow for negative public service motivation $\gamma^{g}$, it is possible that equilibrium wages and prices are such that (25) is negative and decreasing in ability. In contrast to the evidence discussed in the Introduction, this would imply that managers would earn more in the public sector than in the private sector, and that only people with sufficient distaste for working in the public sector would opt for a private management position. Given the evidence, we believe that the results we highlight are most relevant.
} 
increasing in $\alpha_{i}$ :

$$
\frac{d U_{i, m}^{g}}{d \alpha_{i}}=\tilde{m}_{i, m}^{g} p^{g} q_{M}\left(\tilde{n}_{i}^{g} \tilde{e}_{w}^{g}+\tilde{e}_{i, m}^{g}, \alpha_{i} \tilde{m}_{i, m}^{g}\right)>0
$$

where the effects through changes in $\tilde{m}_{i, m}^{g}, \tilde{e}_{i, m}^{g}$, and $\tilde{n}_{i}^{g}$ are zero by the envelop theorem. Equation (27) follows from setting (8) equal to (17), and using $\tilde{m}_{i, m}^{g}+\tilde{e}_{i, m}^{g}=\tilde{e}_{w}^{g}$. From (27) it is clear that $\widehat{\alpha}^{g}$ is independent of $\gamma_{i}^{g}$. Further, since $q(E, 0)=0, h>0$, and $U_{0}>0$ (implying that the left-hand side of (27) is strictly negative when $\alpha=0),(28)$ implies that $\widehat{\alpha}^{g}$ is strictly positive.

Obviously, only individuals with a sufficient level of managerial ability prefer the management position. An important issue is whether this level $\left(\widehat{\alpha}^{g}\right)$ is larger or smaller than the level of managerial ability at which individuals are indifferent between working in and managing a private organisation $\left(\widehat{\alpha}^{k}\right)$, as described by Lemma 3. Comparing (19) and (27), it is clear that this only depends on the wage and price levels in the sectors. While the high price in the private sector implies a relatively low $\widehat{\alpha}^{k}$, the high wage pushes $\widehat{\alpha}^{k}$ in the opposite direction. Generally, one cannot say which of these forces is strongest. This ultimately depends on the properties of the density function $f(\alpha, \gamma)$. For instance, when an intrinsic preference for the public sector is particularly prevalent among potential workers rather than among potential managers, the effect on wages will dominate.

We have shown that there is one intersection between indifference lines 3 and 4. This intersection locates the type that is indifferent between working in the public sector and managing an organisation in either sector. Hence, indifference line 5 must run through the intersection of lines 3 and 4 , which is confirmed by comparing (27) with (22) and (25).

\section{Indifference line 6: Private worker / public manager}

Lastly, consider the choice between working in a private organisation and managing a public organisation. Both good management skills and a large preference for the public sector make it attractive to opt for the management position. An individual $i$ is indifferent when (7) equals (17). Using (9), this can be rewritten to:

$$
\gamma_{i}^{g}=U_{0}-\left[p^{g} q\left(\tilde{n}_{i}^{g} \tilde{e}_{w}^{g}+\tilde{e}_{i, m}^{g}, \alpha_{i} \tilde{m}_{i, m}^{g}\right)-\tilde{n}_{i}^{g} w^{g} \tilde{e}_{w}^{g}-c\left(\tilde{m}_{i, m}^{g}+\tilde{e}_{i, m}^{g}\right)-h\right] .
$$


For individuals with $\alpha_{i}=0$, the first three terms between the brackets in (29) are zero. Hence, only a very positive attitude towards the public sector $\left(\gamma_{i}^{g}=U_{0}+h>0\right)$ would make these untalented individuals indifferent. Line 6 is downward sloping in the $(\alpha, \gamma)$-plane:

$$
\frac{d \gamma_{i}^{g}}{d \alpha_{i}}=-\tilde{m}_{i, m}^{g} p^{g} q_{M}\left(\tilde{n}_{i}^{g} \tilde{e}_{w}^{g}+\tilde{e}_{i, m}^{g}, \alpha_{i} \tilde{m}_{i, m}^{g}\right)<0
$$

where we have again applied the envelop theorem to drop terms related to changes in endogenous variables. As more talented people generate more income as a manager than people with lower $\alpha_{i}$, a lower level of intrinsic utility is sufficient to make them prefer the management job in the public sector. As in the case of line 3, the intercept and slope of line 6 have an unambiguous sign, but the exact shape is unclear:

$$
\frac{d^{2} \gamma_{i}^{g}}{d \alpha_{i}^{2}}=p^{g} q_{M}\left(\frac{q_{M}+2 \alpha_{i} \tilde{m}_{i, m}^{g}\left[q_{M M}-\frac{q_{E M}^{2}}{q_{E E}}\right]}{\alpha_{i}^{2}\left[q_{M M}-\frac{q_{E M}^{2}}{q_{E E}}\right]}\right),
$$

which can be positive or negative.

At the intersection of indifference lines 1 and 4, people are indifferent between being a worker in the private sector and a management position in either sector. Hence, line 6 runs through the intersection of lines 1 and 4 . Similarly, line 6 runs through the intersection of lines 2 and 5 .

\section{The complete picture}

Adding indifference lines 4, 5, and 6 to Figure 1 gives either Figure 2A or Figure 2B. The main difference between these two figures is the position of line 5 compared to line 1 , or, equivalently, the level of $\widehat{\alpha}^{g}$ compared to $\widehat{\alpha}^{k}$. As we have seen, the location of these two lines depends on relative wages and prices in the two sectors. With a relatively high $w^{g}$ and low $p^{g}$, for many individuals the public management position is unattractive compared to either the private management position or the public worker position. Line 5 then lies to the right of line 1. As depicted in Figure 2A, this also implies that line 6 is redundant: There are no individuals who prefer being a worker in the private sector as well as being a manager in the public sector over the two other positions. Hence, the managers in the public sector are contained in the area between line 4 and line 5 . In the other case where wages and prices are more favourable for managers in the public sector, 
public management also becomes attractive to individuals with intermediate ability and motivation. Line 5 then lies to the left of line 1. As depicted in Figure 2B, this implies that the public managers are located in the area between line 4 , line 5 , and line $6 .^{20}$

Comparing the distributions of managerial ability among private and public managers, two results stand out. First, due to the positive slope of line 4 (Proposition 2), there are relatively many managers in the private sector with very high ability. In other words, there is negative selection of managerial ability into the public sector. The intuition behind this result is clear. As we have seen, public service motivation reduces labour cost and yields a nonpecuniary benefit for managers in the public sector. By Lemma 4 , this implies that to have any private production in equilibrium, the output price must be higher in the private sector than in the public sector. As a unit's output increases in managerial ability, the higher output price in the private sector is particularly attractive to good managers. At high levels of ability, managers can earn so much more in the private sector that only a very strong preference for the public sector keeps them from setting up a private firm.

Second, when $\widehat{\alpha}^{g}<\widehat{\alpha}^{k}$ as in Figure 2B, then the economy's least able managers are found in the public sector. The reverse is true when $\widehat{\alpha}^{g}>\widehat{\alpha}^{k}$, a situation that is depicted by Figure 2A. Whether an equilibrium as in Figure 2A or as in Figure 2B arises, crucially depends on the distribution of types, $f(\alpha, \gamma)$. We shall further examine this issue in the next section.

Overall, our results give a bleak picture of the quality of public management: Relatively few among the highly able managers choose careers in public service, and the worst managers may be found in public service. Yet, this is as good as it gets: it is the most efficient way of public production. This follows directly from the absence of market failures in our product and labour markets. In other words, given some level of public production, any attempt to deviate from the effort levels, establishment sizes, or individuals' selection into non-managerial and managerial positions in the public sector that arise under competition only translates into higher cost of public production and, hence, lower welfare. Proposition 3 underlines this result. For

\footnotetext{
${ }^{20}$ Recall that it is possible that line 4 is U-shaped with negative slope in the origin. Then, the intersection of line 3 and line 4 occurs at a negative $\gamma^{g}$ and, hence, to the left of $\widehat{\alpha}^{k}$. It follows that line 5 (i.e. $\widehat{\alpha}^{g}$ ) is located to the left of line 1 . Hence, a situation as depicted in Figure 2B emerges.
} 
the sake of completeness, the proof shows that both a fully informed public monopsonist aiming to minimise the cost of producing a given amount of public sector goods, as well as a social planner aiming to maximise the sum of all individuals' utilities, recruit the same people into public employment, assign them to the same job, and induce the same effort as results under competition. $^{21}$

Proposition 3 The self-selection of individuals into managerial and nonmanagerial positions in the public sector and their choices with respect to effort levels and unit sizes are efficient, both from the perspective of a policy maker aiming to minimise cost of public goods provision and from a socialwelfare perspective.

Proof. See Appendix A.5.

\section{Equilibrium}

In equilibrium, demand for workers must equal supply of workers in both sectors. Prices and wages adjust to attain equilibrium. Since we have assumed that some individuals remain nonemployed and obtain their outside option utility, the wage in the private sector is determined by the participation constraint (9). The wage in the public sector determines both the attractiveness of working in the public sector and the profitability of managing an organisation in the public sector. Therefore, the wage in the public sector affects all indifference lines, except for line 1. Proposition 4 establishes that a higher wage in the public sector implies that more people are willing to become worker in the public sector while demand for public sector workers reduces.

Proposition 4 Suppose $p^{g}$ and $p^{k}$ are such that production takes place in both sectors. Then, for given $p^{g}$ and $p^{k}$, a higher $w^{g}$ leads to greater supply of public sector workers and smaller demand for public sector workers.

\footnotetext{
${ }^{21}$ Note that the fully informed public monopsonist does extract all motivational rents from those in the public sector, by setting an individual's wage such that the participation constraint binds. When individuals' types are private information, the public monopsonist will distort contracts and alter the set of people attracted to the public sector so as to increase rent extraction, as in Delfgaauw and Dur (2008). A full analysis of this case is beyond the scope of this paper.
} 
Proof. See Appendix A.6.

The intuition behind Proposition 4 is given with the help of Figures 2A and $2 \mathrm{~B}$. The types that prefer to be worker in the public sector are in the area contained by line 2, line 5, and, in Figure 2A, line 3 . An increase in the public sector wage makes being a worker in the public sector more attractive relative to being a worker in the private sector (line 2), to being a manager in the public sector (line 5) and to being a manager in the private sector (line 3 ). Hence, lines 2 and 3 shift down and line 5 shifts to the right, thereby increasing the set of types that prefer to become worker in the public sector. Hence, total supply of public sector workers goes up.

For managers in the public sector, an increase in $w^{g}$ makes employing workers more costly. Hence, the option of being a manager in the public sector becomes less attractive relative to being a public sector worker (line 5 ), to being a manager in the private sector (line 4), and to being a private sector worker (line 6 ). Thus, line 5 shifts to the right, and lines 4 and 6 shift upwards. This decreases the number of individuals who want to be manager in the public sector. Moreover, those that remain manager in the public sector optimally reduce the number of workers they employ. As a result, there is less demand for public sector workers.

As demand for public sector workers decreases in $w^{g}$ while the supply increases in $w^{g}$, there is a single value of $w^{g}$ at which the public sector labour market clears for any pair of prices $p^{k}$ and $p^{g}$. Corollary 4.1 underlines this result.

Corollary 4.1 For any given $p^{g}$ and $p^{k}$, where $p^{g}<p^{k}$, there is a unique equilibrium level of $w^{g}$.

Equilibrium comparative statics are straightforward. For instance, consider an exogenous increase in $p^{g}$, e.g. caused by an increased demand for public services. The direct effect is to make managing a public organisation more attractive relative to the other three positions. Thus, some public workers, private managers, and, in the case of Figure 2B, private workers leave their current job to become manager in the public sector. In terms of Figures $2 \mathrm{~A}$ and $2 \mathrm{~B}$, line 5 shifts to the left, and lines 4 and 6 shift downwards. Furthermore, the individuals who were already a public sector manager before the increase in $p^{g}$ expand their production. Hence, demand for public sector workers increases, while supply goes down (as some public workers 
become public manager). To arrive at a new equilibrium, the wage in the public sector must increase. The wage increase implies that public sector managers reduce their production and that lines 4, 5, and 6 move back in the opposite direction compared to the initial effect. Moreover, lines 2 and 3 move downwards, as some workers move from the private to the public sector and, in Figure 2A, some private managers become public workers. The extent of the wage increase relative to the increase in $p^{g}$, which, by Lemma 2, determines whether a given manager in the public sector will produce more or less output compared to the initial situation, depends on the distribution of types $f(\alpha, \gamma)$. Similarly, the net effect on indifference lines 4 , 5 , and 6 and the extent to which line 2 and 3 move also depend on $f(\alpha, \gamma)$.

\section{Concluding Remarks}

We have shown that competition between people with different levels of public service motivation and managerial ability results in a negative selection of managerial ability into the public sector. The willingness of (marginal) public sector workers and managers to accept lower pay in return for (what they perceive as) a more meaningful or enjoyable job translates into lower per-unit output price in the public sector compared to the private sector. This, in turn, creates a public-private earnings penalty for managers which increases in managerial ability. As a result, the relative attractiveness of the public sector decreases in ability, which implies that relatively many of the 'best and brightest' managers of the economy reside in the private sector. Furthermore, the least-able managers may end up in the public sector, and public managers may manage less diligently than private managers with equal ability.

Taken together, these outcomes paint a gloomy picture of public management. Yet, this is efficient: it is the least costly way of producing a given amount of publicly provided goods and results in maximum social welfare as well. This has important repercussions for public sector human resource policies. When public service motivation is sufficiently prevalent in (a subsector of) the public sector, agencies should not aim to recruit and retain the 'best and brightest' managers at all cost, but rather aim at less productive, but better motivated people. Even though this results in relatively weak public management, the benefits of improving the pool of public managers 
by matching remuneration to private sector levels, as called for by various policy reports discussed in the Introduction, are bound to be smaller than the cost.

Throughout, an individual's intrinsic utility has been assumed constant. When public service motivation stems from the joy of helping people, this intrinsic utility may depend on one's effort, especially in non-managerial tasks as these, more so than managerial tasks, may involve helping clients and thereby invoke warm-glow feelings. In our model, linking intrinsic utility to non-managerial effort would strengthen the results. First, it would imply that managers in the public sector have an intrinsic incentive to reduce their managerial effort and increase their effort on non-managerial tasks. Second, as better managers focus more on managerial effort, they derive less intrinsic utility, so that managing a unit in the public sector becomes even less rewarding for high-quality managers relative to less able managers (line 4 pivots counterclockwise). Both of these effects reduce managerial effectiveness in the public sector relative to the private sector. Furthermore, some highly motivated people may refrain from becoming public manager and rather choose to become or remain public worker, because they dread exchanging non-managerial tasks for the intrinsically less rewarding managerial tasks (line 5 rotates clockwise).

The inferior management of public sector organisations implies that productivity is lower than in comparable private sector organisations. Generally, the low productivity and apparent overstaffing of government agencies is attributed to bureaucratic empire-building (Niskanen, 1971) or to political preferences for increased employment (Haskel and Szymanski, 1993; Corneo and Rob, 2003). Our theory suggests an efficiency reason: coupling less productive but highly motivated management to a larger personnel base is cost-efficient. 


\section{A Appendix: Proofs}

For notational convenience, we suppress in this appendix as much as possible the arguments of the derivatives of the production function and the cost function as well as the sub- and superscripts for type $i$, job $j$, and sector $s$.

\section{A.1 Second-order conditons for maximum managers' utility}

First-order conditions (12), (13), and (14) describe a global maximum when the following second-order conditions are satisfied:

$$
\left|\begin{array}{cc}
\alpha^{2} p q_{M M}-c_{m m} & \alpha p q_{M E}-c_{m e} \\
\alpha p q_{M E}-c_{m e} & p q_{E E}-c_{e e}
\end{array}\right|>0
$$

and

$$
\left|\begin{array}{ccc}
\alpha^{2} p q_{M M}-c_{m m} & \alpha p q_{M E}-c_{m e} & \alpha p q_{M E} \\
\alpha p q_{M E}-c_{m e} & p q_{E E}-c_{e e} & p q_{E E} \\
\alpha p q_{M E} & p q_{E E} & p q_{E E}
\end{array}\right|<0 .
$$

Using $c_{m m}=c_{e e}=c_{e m}$, these conditions can be rewritten as:

$$
\begin{gathered}
\alpha^{2} p^{2}\left(q_{M M} q_{E E}-q_{M E}^{2}\right)-c_{e e}\left(\alpha^{2} p q_{M M}+p q_{E E}-2 \alpha p q_{M E}\right)>0 \\
-\alpha^{2} p^{2}\left[q_{M M} q_{E E}-q_{M E}^{2}\right] c_{e e}<0 .
\end{gathered}
$$

As the second term in (30) is positive, it follows from (30) and (31) that if

$$
q_{M M} q_{E E}-q_{M E}^{2}>0
$$

for all $m, e_{m}$, and $n$, then the second-order sufficient conditions for a global maximum are fulfilled.

\section{A.2 Proposition 1}

Applying the implicit function theorem to the system of first-order conditions (12), (13), and (14), we obtain:

$$
\begin{gathered}
d \alpha\left(p q_{M}+m \alpha p q_{M M}\right)+d m\left(\alpha^{2} p q_{M M}-c_{m m}\right)+d e_{m}\left(\alpha p q_{M E}-c_{m e}\right)+d n\left(\alpha e_{w} p q_{M E}\right)=0 \\
d \alpha\left(m p q_{E M}\right)+d m\left(\alpha p q_{E M}-c_{e m}\right)+d e_{m}\left(p q_{E E}-c_{e e}\right)+d n\left(e_{w} p q_{E E}\right)=0
\end{gathered}
$$




$$
d \alpha\left(m p q_{E M}\right)+d m\left(\alpha p q_{E M}\right)+d e_{m}\left(p q_{E E}\right)+d n\left(e_{w} p q_{E E}\right)=0 .
$$

Solving for the effects of an increase in $\alpha$ on $m, e_{m}$, and $n$ gives, respectively:

$$
\begin{gathered}
\frac{d m}{d \alpha}=-\frac{q_{M}+m \alpha\left[q_{M M}-\frac{q_{E M}^{2}}{q_{E E}}\right]}{\alpha^{2}\left[q_{M M}-\frac{q_{E M}^{2}}{q_{E E}}\right]}>0, \\
\frac{d e_{m}}{d \alpha}=-\frac{d m}{d \alpha}<0, \\
\frac{d n}{d \alpha}=-\frac{m q_{E M}}{e_{w} q_{E E}}-\frac{d m}{d \alpha}\left(\frac{\alpha q_{E M}}{e_{w} q_{E E}}-\frac{1}{e_{w}}\right)>0, \\
\frac{d\left(n e_{w}+e_{m}\right)}{d \alpha}=-\frac{m q_{E M}}{q_{E E}}-\frac{d m}{d \alpha}\left(\frac{\alpha q_{E M}}{q_{E E}}\right)>0 .
\end{gathered}
$$

By second-order condition (15) and $q_{E E}<0$, the numerator in (32) is negative. Hence, condition (2) is sufficient to ensure that $\frac{d m}{d \alpha}>0$. The signs of (33), (34), and (35) follow accordingly.

As (32) and (35) imply that both elements in $q(E, M)$ increase with $\alpha$, and $q(E, M)$ is increasing in $\alpha$ for given $E$ and $M$, it follows that output increases in $\alpha$. Substituting (5) into (3), taking the derivative with respect to $\alpha$, and using the envelop theorem shows that utility increases in $\alpha$ :

$$
\frac{\partial U_{m}}{\partial \alpha}=m p q_{M}>0
$$

Likewise, we obtain the comparative static effects of $p$ and $w$, respectively:

$$
\begin{gathered}
\frac{d m}{d p}=-\frac{\left(q_{M} q_{E E}-q_{E} q_{M E}\right)}{\alpha p\left[q_{M M} q_{E E}-q_{E M}^{2}\right]}>0, \\
\frac{d e_{m}}{d p}=-\frac{d m}{d p}<0, \\
\frac{d n}{d p}=-\frac{1}{e_{w} q_{E E}}\left[\frac{q_{E}}{p}+\frac{d m}{d p}\left(\alpha q_{E M}-q_{E E}\right)\right]>0, \\
\frac{d\left(n e_{w}+e_{m}\right)}{d p}=-\frac{1}{q_{E E}}\left[\frac{q_{E}}{p}+\frac{d m}{d p}\left(\alpha q_{E M}\right)\right]>0, \\
\frac{d m}{d w}=-\frac{\left(\alpha q_{M E}-q_{E E}\right)}{\alpha^{2} p\left(q_{M M} q_{E E}-q_{E M}^{2}\right)}<0,
\end{gathered}
$$




$$
\begin{gathered}
\frac{d e_{m}}{d w}=\frac{1}{c_{e e}}-\frac{d m}{d w}>0, \\
\frac{d n}{d w}=-\frac{1}{e_{w} q_{E E}}\left[\frac{d m}{d w}\left(\alpha q_{E M}-q_{E E}\right)+\frac{\left(p q_{E E}-c_{e e}\right)}{p c_{e e}}\right]<0, \\
\frac{d\left(n e_{w}+e_{m}\right)}{d w}=-\frac{1}{q_{E E}}\left[\frac{d m}{d w}\left(\alpha q_{E M}\right)-\frac{1}{p}\right]<0 .
\end{gathered}
$$

\section{A.3 Comparative statics when optimal $e_{m}=0$}

Managers with sufficiently high managerial ability optimally focus on managerial tasks and set $e_{m}=0$. Clearly, at these levels of $\alpha$, we have $\frac{d e_{m}}{d \alpha}=0$. Applying the implicit function theorem to the remaining first-order conditions (12) and (14), we obtain:

$$
\begin{gathered}
d \alpha\left(p q_{M}+m \alpha p q_{M M}\right)+d m\left(\alpha^{2} p q_{M M}-c_{m m}\right)+d n\left(\alpha e_{w} p q_{M E}\right)=0 \\
d \alpha\left(m p q_{E M}\right)+d m\left(\alpha p q_{E M}\right)+d n\left(\tilde{e}_{w}^{k} p q_{E E}\right)=0 .
\end{gathered}
$$

Solving for the effects of an increase in $\alpha$ on $m$ and $n$ gives, respectively:

$$
\begin{gathered}
\frac{d m}{d \alpha}=-\frac{q_{M}+m \alpha\left[q_{M M}-\frac{q_{E M}^{2}}{q_{E E}}\right]}{\alpha^{2}\left[q_{M M}-\frac{q_{E M}^{2}}{q_{E E}}\right]-\frac{c_{m m}}{p}}>0, \\
\frac{d n}{d \alpha}=-\frac{m q_{E M}}{\tilde{e}_{w}^{k} q_{E E}}-\frac{d m}{d \alpha} \frac{\alpha q_{E M}}{\tilde{e}_{w}^{k} q_{E E}}>0 .
\end{gathered}
$$

The signs of (36) and (37) follow from (2) and (15) and are the same as in the case where optimal $e_{m}>0$. Ignoring the effects through changes in the second derivatives of the production function, it is clear that the effects are smaller in magnitude than those above for managers who exert strictly positive non-managerial effort.

Similarly, we obtain the effects of $p$ and $w$, respectively:

$$
\begin{gathered}
\frac{d m}{d p}=-\frac{\alpha\left(q_{M} q_{E E}-q_{M E} q_{E}\right)}{\alpha^{2} p\left[q_{M M} q_{E E}-q_{E M}^{2}\right]-q_{E E} c_{m m}}>0, \\
\frac{d n}{d p}=-\frac{1}{e_{w} q_{E E}}\left[\frac{d m}{d p}\left(\alpha q_{E M}\right)+\frac{q_{E}}{p}\right]>0, \\
\frac{d m}{d w}=-\frac{\alpha q_{M E}}{\alpha^{2} p\left[q_{M M} q_{E E}-q_{E M}^{2}\right]-q_{E E} c_{m m}}<0,
\end{gathered}
$$




$$
\frac{d n}{d w}=\frac{1}{e_{w} p q_{E E}}-\frac{d m}{d p}\left(\frac{\alpha q_{E M}}{e_{w} q_{E E}}\right)<0
$$

\section{A.4 Proposition 2}

In the proof to Proposition 2 in the main text, it is shown that line 4 as described by (25) starts at $\alpha=\gamma^{g}=0$, and that the slope of line 4 as described by (26) is positive for all $\alpha_{i}$ if $\frac{w^{k}}{p^{k}} \leq \frac{w^{g}}{p^{g}}$. Now suppose that $\frac{w^{k}}{p^{k}}>\frac{w^{g}}{p^{g}}$. Using (18), we can rewrite (26) to:

$$
\frac{d \gamma^{g}}{d \alpha}=\frac{1}{\alpha}\left(\tilde{m}_{i}^{k} w^{k}-\tilde{m}_{i}^{g} w^{g}\right)
$$

If $\frac{w^{k}}{p^{k}}>\frac{w^{g}}{p^{g}}$, it follows from Lemma 2 that $\tilde{m}_{i}^{k}<\tilde{m}_{i}^{g}$, implying that (38) can be negative. The effect of $\alpha$ on (38) is given by

$$
\frac{d^{2} \gamma^{g}}{d \alpha^{2}}=\frac{1}{\alpha}\left(\left[\frac{d \tilde{m}_{i}^{k}}{d \alpha}-\frac{\tilde{m}_{i}^{k}}{\alpha}\right] w^{k}-\left[\frac{d \tilde{m}_{i}^{g}}{d \alpha}-\frac{\tilde{m}_{i}^{g}}{\alpha}\right] w^{g}\right)
$$

Using (32), this can be rewritten to

$\frac{d^{2} \gamma^{g}}{d \alpha^{2}}=\frac{1}{\alpha}\left(-\frac{w^{k} \tilde{q}_{M}^{k}}{\alpha^{2}\left[\tilde{q}_{M M}^{k}-\frac{\left(\tilde{q}_{E M}^{k}\right)^{2}}{\tilde{q}_{E E}^{k}}\right]}+\frac{w^{g} \tilde{q}_{M}^{g}}{\alpha^{2}\left[\tilde{q}_{M M}^{g}-\frac{\left(\tilde{q}_{E M}^{g}\right)^{2}}{\tilde{q}_{E E}^{g}}\right]}-\frac{2}{\alpha}\left(\tilde{m}_{i}^{k} w^{k}-\tilde{m}_{i}^{g} w^{g}\right)\right)$,

where the derivatives of $q$ are evaluated at the optimal levels of $m, e_{m}$, and $n$. When (38) is negative (zero), the last term in (39) is positive (zero). By (15) and $q_{E E}<0$, the two denominators in (39) are negative, and if $\frac{w^{k}}{p^{k}}>\frac{w^{g}}{p^{g}}$, it follows from (18) that $\tilde{q}_{M}^{k}>\tilde{q}_{M}^{g}$, implying that $w^{k} \tilde{q}_{M}^{k}>w^{g} \tilde{q}_{M}^{g}$. Hence, if we restrict the third derivatives of $q(E, M)$ such that the difference between the two denominators in (39) is negligible, (39) is always positive for all $\alpha>0$ when (38) is non-positive. Hence, if line 4 has a local extremum, it is a minimum. This implies that if some part of line 4 is downward sloping, line 4 is either downward sloping for all $\alpha \geq 0$ or reaches a minimum at some level of $\alpha$ and has a (weakly) positive slope for higher values of $\alpha$ (that is, line 4 is U-shaped). 
We have shown that line 4 starts at $\alpha=\gamma^{g}=0$ and can have three shapes: upward sloping, downward sloping, or U-shaped. This implies that if there are individuals who prefer to be manager in the private sector rather than manager in the public sector, line 4 must be either upward sloping or U-shaped. In both cases, line 4 is upward sloping in the relevant area where $\alpha>0$ and $\gamma^{g} \geq 0$, as stated in Proposition 2 .

\section{A.5 Proposition 3}

\section{Public monopsonist}

Consider a public monopsonist that aims to minimise the cost of producing a given amount of public sector goods $Q^{g}$. The monopsonist has full information about individuals' type and can verify the effort they exert. It can attract individuals to the public sector by offering wage $w_{i}$ to individual $i$ conditional on the provision of effort levels $e_{i}^{g}$ and $m_{i}^{g}$. Provided that the individual accepts the offer, the monopsonist assigns the individual to a unit and a job within that unit (worker or manager). Individual $i$ accepts the offer when the participation constraint is fulfilled:

$$
w_{i}+\gamma_{i}^{g}-c\left(e_{i}^{g}+m_{i}^{g}\right) \geq \max \left[U_{0}, U_{i, m}^{k}\right]
$$

where $U_{i, m}^{k}$ is utility attained by individual $i$ when managing a unit in the private sector, as given by (16). Using (9) and Lemma 3, we can rewrite this to:

$$
\begin{aligned}
& w_{i} \geq U_{0}-\gamma_{i}^{g}+c\left(e_{i}^{g}+m_{i}^{g}\right) \text { for } \alpha_{i} \leq \widehat{\alpha}^{k}, \\
& w_{i} \geq U_{i, m}^{k}-\gamma_{i}^{g}+c\left(e_{i}^{g}+m_{i}^{g}\right) \text { for } \alpha_{i}>\widehat{\alpha}^{k} .
\end{aligned}
$$

It follows that cost per unit of output decreases with $\gamma^{g}$. Hence, the monopsonist prefers to attract better motivated over less motivated people. Furthermore, as productivity is constant in $\gamma^{g}$ for both public sector jobs and constant in $\alpha$ for public workers and increasing in $\alpha$ for public managers, there can be only one level of $\alpha$ at which the monopsonist is indifferent between assigning people to a managerial job or a non-managerial job. Let $\widehat{\alpha}^{g}$ denote this level of $\alpha$, and let $\gamma_{L}(\alpha)$ be the motivation of the least motivated individual the monopsonist attracts among individuals with ability $\alpha$.

Total cost of public production are given by 


$$
C=\int_{0}^{\bar{\alpha}} \int_{\gamma_{L}(\alpha)}^{\bar{\gamma}} w_{i} f\left(\alpha, \gamma^{g}\right) d \gamma^{g} d \alpha+\int_{\widehat{\alpha}^{g}}^{\bar{\alpha}} \int_{\gamma_{L}(\alpha)}^{\bar{\gamma}} h f\left(\alpha, \gamma^{g}\right) d \gamma^{g} d \alpha,
$$

where the first term gives the total wage bill and the second term gives the total amount spent on setting up units, which cost $h$ per manager. Substituting (41) into (42) gives

$$
\begin{aligned}
C= & \int_{\widehat{\alpha}^{k}}^{\bar{\alpha}} \int_{\gamma_{L}(\alpha)}^{\bar{\gamma}}\left[U_{i, m}^{k}-\gamma_{i}^{g}+c\left(e_{i}^{g}+m_{i}^{g}\right)\right] f\left(\alpha, \gamma^{g}\right) d \gamma^{g} d \alpha \\
& +\int_{0}^{\widehat{\alpha}^{k}} \int_{\gamma_{L}(\alpha)}^{\bar{\gamma}}\left[U_{0}-\gamma_{i}^{g}+c\left(e_{i}^{g}+m_{i}^{g}\right)\right] f\left(\alpha, \gamma^{g}\right) d \gamma^{g} d \alpha \\
& +\int_{\widehat{\alpha}^{g}}^{\bar{\alpha}} \int_{\gamma_{L}(\alpha)}^{\bar{\gamma}} h f\left(\alpha, \gamma^{g}\right) d \gamma^{g} d \alpha .
\end{aligned}
$$

The production constraint states that the sum of the amounts produced in the units of all public managers equals $Q^{g}$ :

$$
Q^{g}=\int_{\widehat{\alpha}^{g}}^{\bar{\alpha}} \int_{\gamma_{L}(\alpha)}^{\bar{\gamma}} q\left(n_{i}^{g} e_{w}^{g}+e_{i, m}^{g}, \alpha_{i} m_{i, m}^{g}\right) f\left(\alpha, \gamma^{g}\right) d \gamma^{g} d \alpha
$$

where we use the fact that workers' productivity is independent of type. Lastly, the monopsonist must obtain sufficient worker effort:

$$
e_{w}^{g} \int_{0}^{\widehat{\alpha}^{g}} \int_{\gamma_{L}(\alpha)}^{\bar{\gamma}} f\left(\alpha, \gamma^{g}\right) d \gamma^{g} d \alpha=e_{w}^{g} \int_{\widehat{\alpha}^{g}}^{\bar{\alpha}} \int_{\gamma_{L}(\alpha)}^{\bar{\gamma}} n_{i}^{g} f\left(\alpha, \gamma^{g}\right) d \gamma^{g} d \alpha .
$$

The monopsonist minimises (43) with respect to $\widehat{\alpha}^{g}, \gamma_{L}(\alpha), e_{w}^{g}, e_{i, m}^{g}, m_{i, m}^{g}$, and $n_{i}^{g}$ for all $\alpha$, subject to the production constraint (44) and the worker effort constraint (45). For ease of exposition, we neglect the constraint that $\gamma_{L}(\alpha) \leq \bar{\gamma}$ for all $\alpha$.

After some rewriting, the Lagrangian equation reads 


$$
\begin{aligned}
\Gamma= & \int_{\widehat{\alpha}^{k}}^{\bar{\alpha}} \int_{\gamma_{L}(\alpha)}^{\bar{\gamma}}\left[U_{i, m}^{k}-\gamma_{i}^{g}+c\left(e_{i}^{g}+m_{i}^{g}\right)\right] f\left(\alpha, \gamma^{g}\right) d \gamma^{g} d \alpha \\
& +\int_{0}^{\widehat{\alpha}^{k}} \int_{\gamma_{L}(\alpha)}^{\bar{\gamma}}\left[U_{0}-\gamma_{i}^{g}+c\left(e_{i}^{g}+m_{i}^{g}\right)\right] f\left(\alpha, \gamma^{g}\right) d \gamma^{g} d \alpha \\
& +\int_{\widehat{\alpha}^{g}}^{\bar{\alpha}} \int_{\gamma_{L}(\alpha)}^{\bar{\gamma}}\left[h-\lambda_{1} q\left(n_{i}^{g} e_{w}^{g}+e_{i, m}^{g}, \alpha_{i} m_{i, m}^{g}\right)+\lambda_{2} e_{w}^{g} n_{i}^{g}\right] f\left(\alpha, \gamma^{g}\right) d \gamma^{g} d \alpha \\
& +\lambda_{1} Q^{g}-\lambda_{2}\left\{\int_{0}^{\widehat{\alpha}^{g}} \int_{\gamma_{L}(\alpha)}^{\bar{\gamma}} e_{w}^{g} f\left(\alpha, \gamma^{g}\right) d \gamma^{g} d \alpha\right\},
\end{aligned}
$$

where $\lambda_{1}$ and $\lambda_{2}$ are the Lagrange multipliers for the production constraint (44) and the worker effort constraint (45), respectively.

The first-order conditions with respect to $e_{i, m}^{g}, m_{i, m}^{g}$, and $n_{i}^{g}$ for public managers with ability $\alpha_{i}$ are given by, respectively:

$$
\begin{gathered}
-\lambda_{1} q_{E}\left(n_{i}^{g} e_{w}^{g}+e_{i, m}^{g}, \alpha_{i} m_{i, m}^{g}\right)+c_{E}\left(e_{i}^{g}+m_{i}^{g}\right)=0, \\
-\lambda_{1} \alpha_{i} q_{M}\left(n_{i}^{g} e_{w}^{g}+e_{i, m}^{g}, \alpha_{i} m_{i, m}^{g}\right)+c_{M}\left(e_{i}^{g}+m_{i}^{g}\right)=0, \\
-\lambda_{1} q_{E}\left(n_{i}^{g} e_{w}^{g}+e_{i, m}^{g}, \alpha_{i} m_{i, m}^{g}\right)+\lambda_{2}=0 .
\end{gathered}
$$

Comparison with (12) - (14) shows that with $\lambda_{1}$ and $\lambda_{2}$ taking the role of $p^{g}$ and $w^{g}$, respectively, these first-order conditions are identical to those for optimal managerial choices under competition. The first-order condition with respect to $e_{w}^{g}$ gives for every public worker, using (46)

$$
-\lambda_{2}+c_{E}\left(e_{w}^{g}\right)=0
$$

which is identical to the first-order condition for optimal worker effort under competition (6) when $\lambda_{2}=w^{g}$. The first-order condition with respect to $\widehat{\alpha}^{g}$ gives

$$
-\int_{\gamma_{L}(\alpha)}^{\bar{\gamma}}\left[h-\lambda_{1} q\left(n_{i}^{g} e_{w}^{g}+e_{i, m}^{g}, \widehat{\alpha}^{g} m_{i, m}^{g}\right)+\lambda_{2} e_{w}^{g}\left(n_{i}+1\right)\right] f\left(\widehat{\alpha}^{g}, \gamma^{g}\right) d \gamma^{g}=0
$$

such that $\widehat{\alpha}^{g}$ is defined by $-\lambda_{1} q\left(n_{i}^{g} e_{w}^{g}+e_{i, m}^{g}, \widehat{\alpha}^{g} m_{i, m}^{g}\right)+\lambda_{2} e_{w}^{g}\left(n_{i}+1\right)+h=$ 0 , which is identical to the definition of $\widehat{\alpha}^{g}$ under competition (27) when $\lambda_{1}=p^{g}$ and $\lambda_{2}=w^{g}$. Lastly, the first-order condition with respect to $\gamma_{L}(\alpha)$ 
gives

$$
\begin{gathered}
-\int_{\widehat{\alpha}^{k}}^{\bar{\alpha}}\left[U_{i, m}^{k}-\gamma_{L}(\alpha)+c\left(e_{i}^{g}+m_{i}^{g}\right)\right] f\left(\alpha, \gamma_{L}(\alpha)\right) d \alpha-\int_{0}^{\widehat{\alpha}^{k}}\left[U_{0}-\gamma_{L}(\alpha)+c\left(e_{i}^{g}+m_{i}^{g}\right)\right] f\left(\alpha, \gamma_{L}(\alpha)\right) d \alpha \\
-\int_{\widehat{\alpha}^{g}}^{\bar{\alpha}}\left[h-\lambda_{1} q\left(n_{i}^{g} e_{w}^{g}+e_{i, m}^{g}, \alpha_{i} m_{i, m}^{g}\right)+\lambda_{2} e_{w}^{g} n_{i}^{g}\right] f\left(\alpha, \gamma_{L}(\alpha)\right)^{g} d \alpha+\lambda_{2}\left\{\int_{0}^{\widehat{\alpha}^{g}} e_{w}^{g} f\left(\alpha, \gamma_{L}(\alpha)\right) d \alpha\right\}=0 .
\end{gathered}
$$

Hence, for any public worker with $\alpha \leq \widehat{\alpha}^{k}$, it must hold that $U_{0}-\gamma_{L}(\alpha)+$ $c\left(e_{w}^{g}\right)-\lambda_{2} e_{w}^{g}=0$. Similarly, for public workers with $\alpha>\widehat{\alpha}^{k}$, it must hold that $U_{i, m}^{k}-\gamma_{L}(\alpha)+c\left(e_{i}^{g}+m_{i}^{g}\right)-\lambda_{2} e_{w}^{g}=0$. Using (16), the relation between $\gamma_{L}(\alpha)$ and $\alpha$ for public workers is given by

$$
\begin{aligned}
& \frac{d \gamma_{L}(\alpha)}{d \alpha}=0 \text { for } \alpha_{i} \leq \widehat{\alpha}^{k} \\
& \frac{d \gamma_{L}(\alpha)}{d \alpha}=\tilde{m}_{i, m}^{k} p^{k} q_{M}\left(\tilde{n}_{i}^{k} \tilde{e}_{w}^{k}+\tilde{e}_{i, m}^{k}, \alpha_{i} \tilde{m}_{i, m}^{k}\right) \text { for } \alpha_{i}>\widehat{\alpha}^{k},
\end{aligned}
$$

where all effects of $\alpha$ through $e_{w}^{g}, \tilde{e}_{w}^{k}, \tilde{m}_{i, m}^{k}$, and $\tilde{n}_{i}^{k}$ are zero by the envelop theorem. Both levels and slopes of $\gamma_{L}(\alpha)$ are identical to those defining indifference lines 2 and 3 under competition, respectively, when $\lambda_{1}=p^{g}$ and $\lambda_{2}=w^{g}$.

For any public manager with $\alpha \leq \widehat{\alpha}^{k}$, it must hold that $U_{0}-\gamma_{L}(\alpha)+$ $c\left(e_{i}^{g}+m_{i}^{g}\right)+h-\lambda_{1} q\left(n_{i}^{g} e_{w}^{g}+e_{i, m}^{g}, \alpha_{i} m_{i, m}^{g}\right)+\lambda_{2} e_{w}^{g} n_{i}^{g}=0$, and for public managers with $\alpha>\widehat{\alpha}^{k}$, it must hold that $U_{i, m}^{k}+h-\gamma_{L}(\alpha)+c\left(e_{i}^{g}+m_{i}^{g}\right)-$ $\lambda_{1} q\left(n_{i}^{g} e_{w}^{g}+e_{i, m}^{g}, \alpha_{i} m_{i, m}^{g}\right)+\lambda_{2} e_{w}^{g} n_{i}=0$. The relation between $\gamma_{L}(\alpha)$ and $\alpha$ for public managers is given by

$$
\begin{aligned}
& \frac{d \gamma_{L}(\alpha)}{d \alpha}=-\lambda_{1} m_{i, m}^{g} q\left(n_{i}^{g} e_{w}^{g}+e_{i, m}^{g}, \alpha_{i} m_{i, m}^{g}\right) \text { for } \alpha_{i} \leq \widehat{\alpha}^{k} \\
& \frac{d \gamma_{L}(\alpha)}{d \alpha}=\tilde{m}_{i, m}^{k} p^{k} q_{M}\left(\tilde{n}_{i}^{k} \tilde{e}_{w}^{k}+\tilde{e}_{i, m}^{k}, \alpha_{i} \tilde{m}_{i, m}^{k}\right)-\lambda_{1} m_{i, m}^{g} q\left(n_{i}^{g} e_{w}^{g}+e_{i, m}^{g}, \alpha_{i} m_{i, m}^{g}\right) \text { for } \alpha_{i}>\widehat{\alpha}^{k},
\end{aligned}
$$

where again all effects of $\alpha$ through $e_{w}^{g}, \tilde{e}_{w}^{k}, \tilde{m}_{i, m}^{k}$, and $\tilde{n}_{i}^{k}$ are zero by the envelop theorem. Both levels and slopes of $\gamma_{L}(\alpha)$ are identical to those defining indifference lines 6 and 4 under competition, respectively, when $\lambda_{1}=p^{g}$ and $\lambda_{2}=w^{g}$.

Noting that the public monopsonist must meet the marginal workers' and marginal managers' participation constraints, it follows that the shadow price of public output $\lambda_{1}$ and the shadow price of worker's effort $\lambda_{2}$ equal $p^{g}$ 
and $w^{g}$, respectively. Hence, our results above imply that the public monopsonist recruits the same individuals, assigns them to the same position, and induces similar effort levels and unit sizes as arise under competition, given the level of public production.

\section{Social planner}

Now consider a social planner that wants to maximise welfare, defined as the sum of all individuals' utility minus the cost of public production, ${ }^{22}$ subject to the constraints (44) and (45). Again, the planner has full information about individuals' type and can contract on the effort they exert. It can attract individuals to the public sector and assign them to a unit and job by offering wage $w_{i}$ to individual $i$ conditional on the provision of effort levels $e_{i}^{g}$ and $m_{i}^{g}$ and subject to the participation constraint (40). Utility of individual $i$ in the public sector is given by $w_{i}+\gamma_{i}^{g}-c\left(e_{i}^{g}+m_{i}^{g}\right)$. Utility of individual $i$ in the private sector is given by $\max \left[U_{0}, U_{i, m}^{k}\right]$. Clearly, the social planner prefers to attract better motivated over less motivated people to the public sector, and assigns the most able individuals it attract to managerial positions. Total welfare is given by

$$
\begin{aligned}
\Psi= & \int_{\widehat{\alpha}^{k}}^{\bar{\alpha}} \int_{0}^{\gamma_{L}(\alpha)} U_{i, m}^{k} f\left(\alpha, \gamma^{g}\right) d \gamma d \alpha+\int_{0}^{\widehat{\alpha}^{k}} \int_{0}^{\gamma_{L}(\alpha)} U_{0} f\left(\alpha, \gamma^{g}\right) d \gamma d \alpha \\
& +\int_{0}^{\bar{\alpha}} \int_{\gamma_{L}(\alpha)}^{\bar{\gamma}}\left\{w_{i}+\gamma_{i}^{g}-c\left(e_{i}^{g}+m_{i}^{g}\right)\right\} f\left(\alpha, \gamma^{g}\right) d \gamma d \alpha \\
& -\int_{0}^{\bar{\alpha}} \int_{\gamma_{L}(\alpha)}^{\bar{\gamma}} w_{i} f\left(\alpha, \gamma^{g}\right) d \gamma d \alpha-\int_{\widehat{\alpha}^{g}}^{\bar{\alpha}} \int_{\gamma_{L}(\alpha)}^{\bar{\gamma}} h f\left(\alpha, \gamma^{g}\right) d \gamma^{g} d \alpha, \quad
\end{aligned}
$$

where the first line gives the utility of all individuals in the private sector, the second line describes the utility of all individuals attracted to the public sector, and the last two terms give the public sector wage bill and fixed unit cost, respectively. Note that we can rewrite (47) such that $w_{i}$ drops out. Clearly, since taxes are nondistortionary and utility linear in income, public sector wages do not affect total welfare (but must fulfill the individual's participation constraint). After some straightforward algebra, social welfare

\footnotetext{
${ }^{22}$ Recall that, when defining an individual's utility, we ignored taxation for notational convenience. This was innocuous, as taxes are lump-sum. Here, however, we need to take the level of taxes into account as it does affect individuals' utilities and, hence, social welfare. Hence, we substract the cost of public production (which equal the level of taxes) from the sum of individuals' utility.
} 
(47) can be rewritten as

$$
\begin{aligned}
\Psi= & \int_{\widehat{\alpha}^{k}}^{\bar{\alpha}} \int_{\gamma_{L}(\alpha)}^{\bar{\gamma}}\left[\gamma_{i}^{g}-c\left(e_{i}^{g}+m_{i}^{g}\right)-U_{i, m}^{k}\right] f\left(\alpha, \gamma^{g}\right) d \gamma d \alpha \\
& +\int_{0}^{\widehat{\alpha}^{k}} \int_{\gamma_{L}(\alpha)}^{\bar{\gamma}}\left[\gamma_{i}^{g}-c\left(e_{i}^{g}+m_{i}^{g}\right)-U_{0}\right] f\left(\alpha, \gamma^{g}\right) d \gamma d \alpha \\
& -\int_{\widehat{\alpha}^{g}}^{\bar{\alpha}} \int_{\gamma_{L}(\alpha)}^{\bar{\gamma}} h f\left(\alpha, \gamma^{g}\right) d \gamma d \alpha+\int_{0}^{\bar{\alpha}} \int_{0}^{\bar{\gamma}} U_{i, m}^{k} d \gamma d \alpha .
\end{aligned}
$$

This objective function is identical to the objective function (43) minimised by the monopsonist, expect for the signs (which are, naturally, opposite) and the last term (which is a constant). Hence, social-welfare maximisation, costminimisation, and perfect competition yield the same selection of people to sectors and positions as well as identical levels of effort and unit size.

\section{A.6 Proposition 4}

From Figures 2A and 2B, it follows that the supply of workers in the public sector is given by the area in between indifference line 2, line 5, and, in Figure $2 \mathrm{~A}$, line 3 . The two cases depicted by Figures $2 \mathrm{~A}$ and $2 \mathrm{~B}$ give rise to the following expressions for the supply of public sector workers, respectively:

$$
\begin{aligned}
S^{2 A} & =N \int_{0}^{\widehat{\alpha}^{k}} \int_{\widehat{\gamma}}^{\bar{\gamma}} f(\alpha, \gamma) d \gamma d \alpha+N \int_{\widehat{\alpha}^{k}}^{\widehat{\alpha}_{3}^{g}(\alpha)} \int_{\widehat{\alpha}^{g}}^{\bar{\gamma}} f(\alpha, \gamma) d \gamma d \alpha, \\
S^{2 B} & =N \int_{0}^{\bar{\gamma}} \int_{\widehat{\gamma}} f(\alpha, \gamma) d \gamma d \alpha .
\end{aligned}
$$

where $\gamma_{3}^{g}(\alpha)$ denotes the level of $\gamma^{g}$ as described by (22) (line 3) and recall that $N$ is defined as the total number of people in the economy. From (11), we know that $\frac{\partial \widehat{\gamma}}{\partial w^{g}}=-\tilde{e}_{w}^{g}<0$. Similarly, using (10) and differentiating (22) with respect to $w^{g}$ gives $\frac{\partial \gamma_{3}^{g}(\alpha)}{\partial w^{g}}=-\tilde{e}_{w}^{g}<0$. Applying the implicit function theorem to (27), the effect of $w^{g}$ on $\widehat{\alpha}^{g}$ (line 5) is given by $\frac{\partial \widehat{\alpha}^{g}}{\partial w^{g}}=$ 
$\frac{(\tilde{n}+1) \tilde{e}_{w}^{g}}{\tilde{m} p^{g} q_{M}}>0$. Using Leibniz' rule, we obtain:

$$
\begin{aligned}
\frac{\partial S^{2 A}}{\partial w^{g}} & =-N \int_{0}^{\widehat{\alpha}^{k}} f(\alpha, \widehat{\gamma}) \frac{\partial \widehat{\gamma}}{\partial w^{g}} d \alpha-N \int_{\widehat{\alpha}^{k}}^{\widehat{\alpha}^{g}} f\left(\alpha, \gamma_{3}^{g}(\alpha)\right) \frac{\partial \gamma_{3}^{g}(\alpha)}{\partial w^{g}} d \alpha+N \int_{\gamma_{3}^{g}\left(\widehat{\alpha}^{g}\right)}^{\bar{\gamma}} f\left(\widehat{\alpha}^{g}, \gamma\right) \frac{\partial \widehat{\alpha}^{g}}{\partial w^{g}} d \gamma>0, \\
\frac{\partial S^{2 B}}{\partial w^{g}} & =N \int_{\widehat{\gamma}} f\left(\widehat{\alpha}^{g}, \gamma\right) \frac{\partial \widehat{\alpha}^{g}}{\partial w^{g}} d \gamma-N \int_{0}^{\widehat{\alpha}^{g}} f(\alpha, \widehat{\gamma}) \frac{\partial \widehat{\gamma}}{\partial w^{g}} d \alpha>0 .
\end{aligned}
$$

Hence, supply increases in $w^{g}$.

The demand of public sector workers is determined by managers in the public sector. From Figures $2 \mathrm{~A}$ and $2 \mathrm{~B}$, it follows that public sector managers are contained in the area between line 4, line 5, and, in Figure 2B, line 6. Let $\gamma_{4}^{g}(\alpha)$ be the level of $\gamma^{g}$ as determined by (25), at which people are indifferent between managing in the private and the public sector (line 4 ), and let $\gamma_{6}^{g}(\alpha)$ be the level of $\gamma^{g}$ as determined by (29), at which people are indifferent between working in the private sector and managing in the public sector (line 6). The demand for public sector workers in the cases depicted by Figures $2 \mathrm{~A}$ and $2 \mathrm{~B}$ is given by, respectively:

$$
\begin{aligned}
D^{2 A} & =N \int_{\widehat{\alpha}^{g}}^{\bar{\alpha}} \int_{\gamma_{4}^{g}(\alpha)}^{\bar{\gamma}} \tilde{n}(\alpha) f(\alpha, \gamma) d \gamma d \alpha \\
D^{2 B} & =N \int_{\widehat{\alpha}^{g}}^{\widehat{\alpha}^{k}} \int_{\gamma_{6}^{g}(\alpha)}^{\bar{\gamma}} \tilde{n}(\alpha) f(\alpha, \gamma) d \gamma d \alpha+N \int_{\widehat{\alpha}^{k}}^{\bar{\alpha}} \int_{\gamma_{4}^{g}(\alpha)}^{\bar{\gamma}} \tilde{n}(\alpha) f(\alpha, \gamma) d \gamma d \alpha .
\end{aligned}
$$

Differentiating $\gamma_{4}^{g}(\alpha)$ and $\gamma_{6}^{g}(\alpha)$ with respect to $w^{g}$ gives $\frac{\partial \gamma_{4}^{g}(\alpha)}{\partial w^{g}}=\frac{\partial \gamma_{6}^{g}(\alpha)}{\partial w^{g}}=$ $\tilde{n} \tilde{e}_{w}>0$. Furthermore, from Proposition 1 we know that $\frac{\partial \tilde{n}(\alpha)}{\partial w^{g}}<0$. Using 
Leibniz' rule, we obtain:

$$
\begin{gathered}
\frac{\partial D^{2 A}}{\partial w^{g}}=N \int_{\widehat{\alpha}^{g}}^{\bar{\alpha}} \int_{\gamma_{4}^{g}(\alpha)}^{\bar{\gamma}} \frac{\partial \tilde{n}(\alpha)}{\partial w^{g}} f(\alpha, \gamma) d \gamma d \alpha-N \int_{\gamma_{4}^{g}\left(\widehat{\alpha}^{g}\right)}^{\bar{\gamma}} \tilde{n}\left(\widehat{\alpha}^{g}\right) f\left(\widehat{\alpha}^{g}, \gamma\right) \frac{\partial \widehat{\alpha}^{g}}{\partial w^{g}} d \gamma \\
-N \int_{\widehat{\alpha}^{g}}^{\bar{\alpha}} \tilde{n}(\alpha) f\left[\alpha, \gamma_{4}^{g}(\alpha)\right] \frac{\partial \gamma_{4}^{g}(\alpha)}{\partial w^{g}} d \alpha<0, \\
\frac{\partial D^{2 B}}{\partial w^{g}}=N \int_{\widehat{\alpha}^{g}} \int_{\gamma_{6}^{g}(\alpha)}^{\bar{\gamma}} \frac{\partial \tilde{n}(\alpha)}{\partial w^{g}} f(\alpha, \gamma) d \gamma d \alpha-N \int_{\widehat{\gamma}_{6}^{g}\left(\widehat{\alpha}^{g}\right)}^{\bar{\gamma}} \tilde{n}\left(\widehat{\alpha}^{g}\right) f\left(\widehat{\alpha}^{g}, \gamma\right) \frac{\partial \widehat{\alpha}^{g}}{\partial w^{g}} d \gamma \\
-N \int_{\widehat{\alpha}^{g}} \tilde{n}^{k}(\alpha) f\left[\alpha, \gamma_{6}^{g}(\alpha)\right] \frac{\partial \gamma_{6}^{g}(\alpha)}{\partial w^{g}} d \alpha+N \int_{\widehat{\alpha}^{k} \gamma_{4}^{g}(\alpha)}^{\bar{\gamma}} \frac{\partial \tilde{n}(\alpha)}{\partial w^{g}} f(\alpha, \gamma) d \gamma d \alpha \\
-N \int_{\widehat{\alpha}^{k}}^{\bar{n}} \tilde{n}(\alpha) f\left[\alpha, \gamma_{4}^{g}(\alpha)\right] \frac{\partial \gamma_{4}^{g}(\alpha)}{\partial w^{g}} d \alpha<0 .
\end{gathered}
$$

Hence, the demand for public sector workers decreases in $w^{g}$, through two channels. First, less people are willing to become manager in the public sector. Second, those that remain reduce the number of workers they employ. 


\section{References}

[1] Abowd, John, Kramarz, Francis., and Margolis, David (1999), High wage workers and high wage firms. Econometrica, vol. 67 (2), pp. 251333.

[2] Antonazzo, Emanuela, Scott, Anthony, Skatun, Diane, and Elliot, Robert F. (2003), The Labour Market for Nursing: A Review of the Labour Supply Literature, Health Economics, vol. 12 (6), pp. 465-478.

[3] Bargain, Olivier, and Melly, Blaise (2008), Public Sector Pay Gap in France: New Evidence Using Panel Data, IZA Discussion Paper No. 3427 .

[4] Besley, Timothy and Ghatak, Maitreesh (2005), Competition and Incentives with Motivated Agents, American Economic Review, vol. 95 (3), pp. 616-636.

[5] Boyne, George (2002), Public and Private Management: What is the Difference? Journal of Management Studies, vol. 39 (1), pp. 97-122.

[6] Brown, C. (1980), Equalizing Differences in the Labor Market, Quarterly Journal of Economics vol. 94, pp. 113-134.

[7] Corneo, Giacomo, and Rob, Rafael (2003), Working in public and private firms, Journal of Public Economics, vol. 87 (7-8), pp. 1335-1352.

[8] Costrell, Robert, and Loury, Glenn (2004), Distribution of Ability and Earnings in a Hierarchical Job Assignment Model, Journal of Political Economy, vol. 112 (6), pp. 1322-1363.

[9] Delfgaauw, Josse, and Dur, Robert (2007), Signaling and Screening of Workers' Motivation, Journal of Economic Behavior and Organization, vol. 62 (4), pp. 605-624.

[10] Delfgaauw, Josse, and Dur, Robert (2008), Incentives and Workers' Motivation in the Public Sector, Economic Journal, vol. 118 (525), pp. 171-191.

[11] Disney, Richard, and Gosling, Amanda (1998), Does it Pay to Work in the Public Sector?, Fiscal Studies, vol. 19, pp. 347-374. 
[12] Dixit, Avinash (2002), Incentives and Organizations in the Public Sector: An Interpretative Review, Journal of Human Resources, vol. 37 (4), pp. 696-727.

[13] Edmonds, Suzanne, Sharp, Caroline, and Benefield, Pauline (2002), Recruitment to and Retention on Initial Teacher Training - A Systematic Review, Slough: National Foundation for Educational Research.

[14] Frank, Sue A., and Lewis, Gregory B. (2004), Government Employees: Working Hard or Hardly Working?, American Review of Public Administration, vol. 34 (1), pp. 36-51.

[15] Gibbons, Robert, and Katz, Lawrence, (1992), Does unmeasured ability explain inter-industry wage differentials? Review of Economic Studies, vol. 59 (3), pp. 515-535.

[16] Gibbons, Robert, and Waldman, Michael (1999), Careers in Organizations: Theory and Evidence. In: O. Ashenfelter and D. Card (Eds.) Handbook of Labor Economics, Vol. 3B. North Holland, pp. 2373-2437.

[17] Gibbons, Robert, and Waldman, Michael (2006), Enriching a Theory of Wage and Promotion Dynamics Inside Firms, Journal of Labor Economics, vol. 24, pp. 59-107.

[18] Goddeeris, John (1988), Compensating Differentials and Self-Selection: An Application to Lawyers, Journal of Political Economy, vol. 96 (2), pp. $411-428$.

[19] Goux, D. and Maurin, E., (1999), Persistence of interindustry wage differentials: A reexamination using matched worker-firm panel data. Journal of Labor Economics, vol. 17 (3), pp. 492-533.

[20] Handy, F. and Katz, E., (1998), The wage differential between nonprofit institutions and corporations: Getting more by paying less? Journal of Comparative Economics, vol. 26, pp. 246-261.

[21] Haskel, Jonathan, and Szymanski, Stefan (1993), Privatization, liberalization, wages and employment: theory and evidence for the UK, Economica, vol. 60 (May), pp. 161-181. 
[22] Hwang, Hae-shin, Reed, W. Robert, Hubbard, Carlton (1992), Compensating Wage Differentials and Unobserved Productivity, Journal of Political Economy, vol. 100 (2), pp. 835-858.

[23] Krueger, Alan, and Summers, Lawrence, (1988), Efficiency wages and the inter-industry wage structure, Econometrica, vol. 56, pp. 259-293.

[24] Kwon, Illong (2006), Incentives, Wages, and Promotions: Theory and Evidence, RAND Journal of Economics, vol. 37 (1), pp. 100-120.

[25] Le Grand, Julien (2003), Motivation, Agency, and Public Policy; Of Knights and Knaves, Pawns and Queens, Oxford: Oxford University Press.

[26] Melly, Blaise (2005), Public-Private Wage Differentials in Germany: Evidence from Quantile Regression, Empirical Economics, vol. 30 (2), ppp. 505-520.

[27] Mocan, Naci, and Tekin, Erdal (2003), Nonprofit Sector and Part-Time Work: An Analysis of Employer-Employee Matched Data of Child Care Workers, Review of Economics and Statistics, vol. 85 (1) pp. 38-50.

[28] National Commission on the Public Service (2003), Urgent Business for America: Revitalizing the Federal Government for the 21st Century, Washington, DC: The Brookings Institution.

[29] OECD, 2001. Public sector - An employer of choice? Report on the competitive employer project. OECD Public Management Service.

[30] Perry, James, and Hondeghem, Annie (2008), Motivation in Public Management: The Call of Public Service, Oxford: Oxford University Press.

[31] Poterba, James, and Rueben, Kim (1994), The Distribution of Public Sector Wage Premia: New Evidence Using Quantile Regression Methods, NBER Working Paper No. 4734.

[32] Prendergast, Canice, (2007), The Motivation and Bias of Bureaucrats, American Economic Review, vol. 97 (1), pp. 180-196.

[33] Preston, Anne (1989), The nonprofit worker in a for-profit world, Journal of Labor Economics vol. 7, pp. 438-463. 
[34] Roomkin, Myron, and Weisbrod, Burton (1999), Managerial Compensation and Incentives in For-Profit and Nonprofit Hospitals, Journal of Law, Economics, and Organization, vol. 15 (3), pp. 750-781.

[35] Rose-Ackerman, Susan, (1996), Altruism, nonprofits and economic theory, Journal of Economic Literature, vol. 34, pp. 701-728.

[36] Rosen, Sherwin (1974), Hedonic prices and implicit markets: product differentiation in pure competition, Journal of Political Economy, vol. 82 (1), pp. 34-55.

[37] Rosen, Sherwin (1982), Authority, Control, and the Distribution of Earnings. Bell Journal of Economics, vol.13 (2), pp. 311-323.

[38] Rosen, Sherwin (1986), The Theory of Equalizing Differences. In: O. Ashenfelter and R. Layard (Eds.) Handbook of Labor Economics, Vol. 1. North Holland, pp. 641-692.

[39] Waldman, Michael (1984), Worker Allocation, Hierarchies, and the Wage Distribution, Review of Economic Studies, vol. 51, pp. 95-109.

[40] Weisbrod, Burton (1983), Nonprofit and Proprietary Sector Behavior: Wage Differentials among Lawyers, Journal of Labor Economics vol. 1, pp. 246-263. 


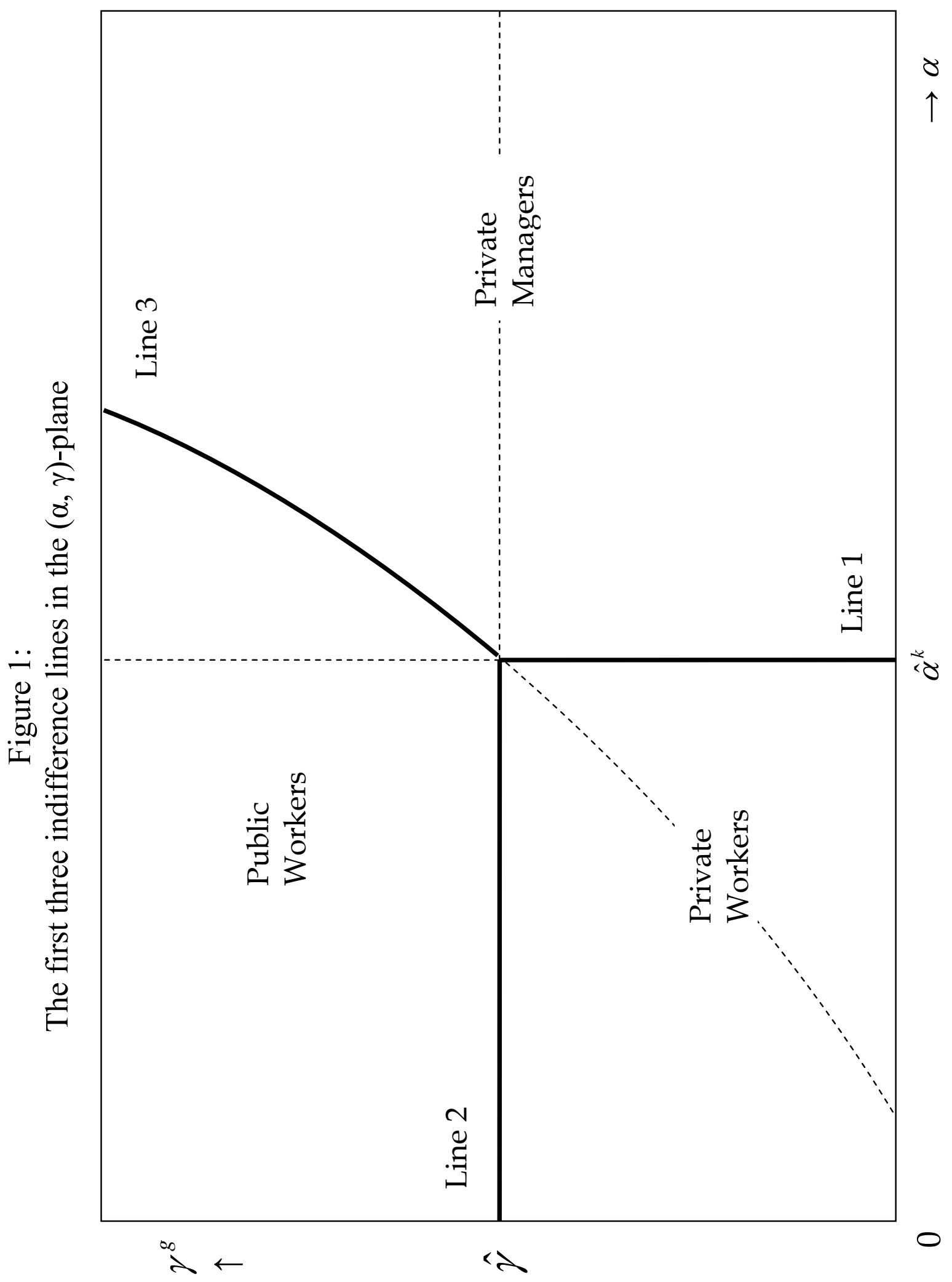




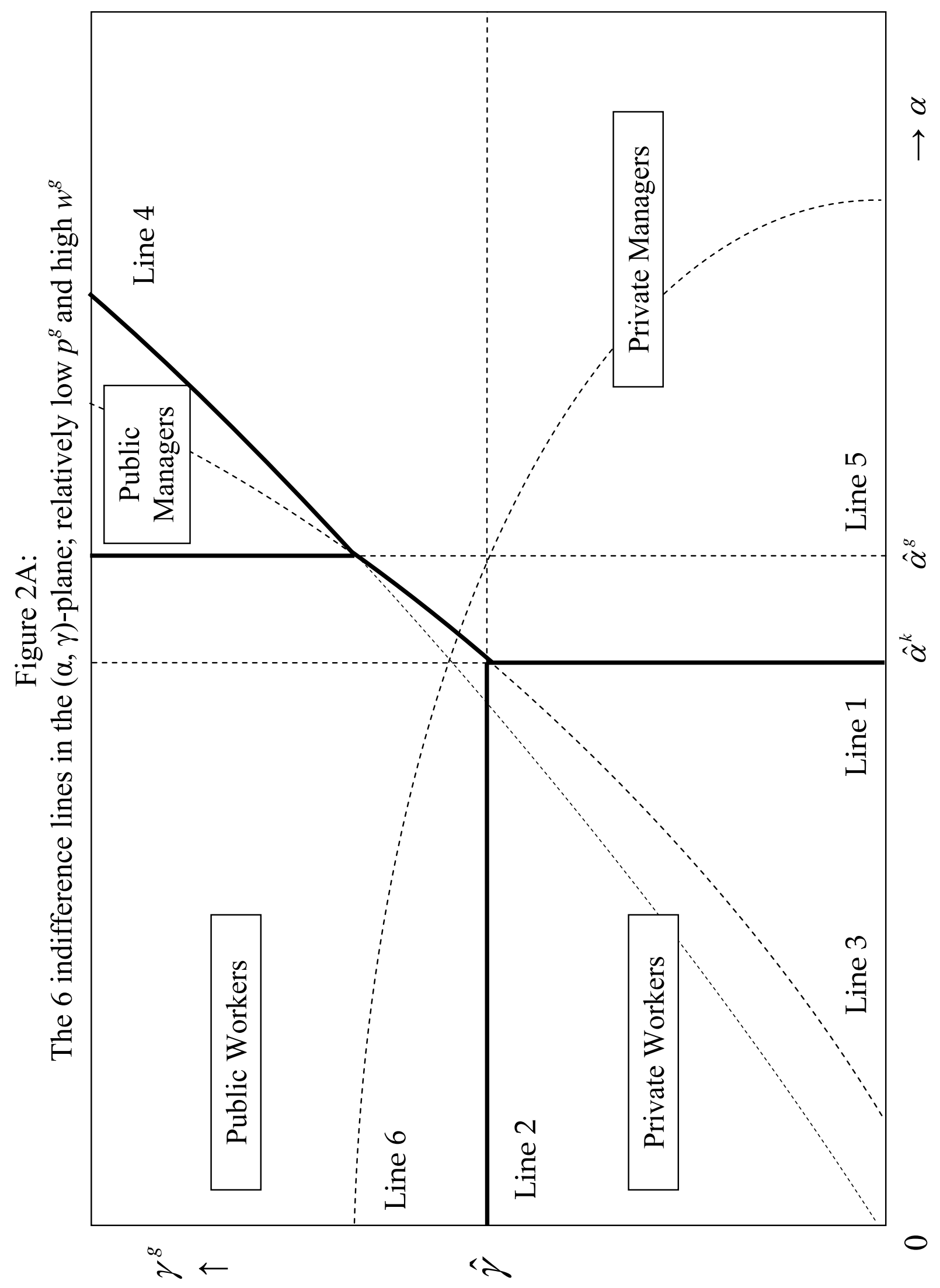




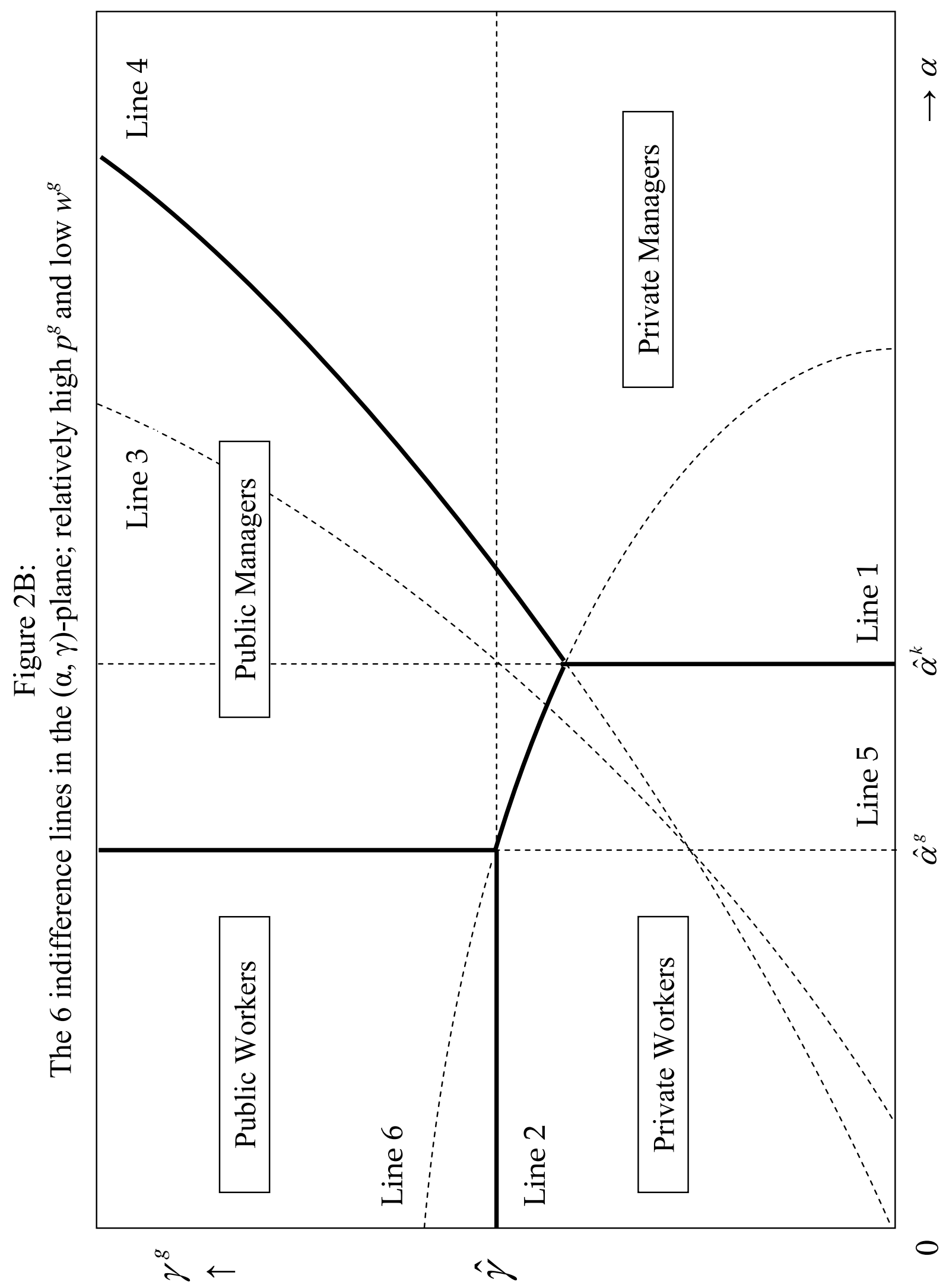

